SANDIA REPORT BECF:

SAND99-0099

Unlimited Release

Printed January 1999

FEP

4 A4S 0619 Rewand-Approtat Desk

FG DOEOSTI, 15102

651

\title{
Subsidence at the Weeks Island SPR
}

Facility

Stephen J. Bauer

Prepared by

Sandia National Laboratories

Abuquerque. New Mexico 87185 and Livermore, California 94550

Sandia is a multiprogram laboratory operated by Sandia Corporation,

a Lockheed Martin Company, for the United States Department of

Energy under Contract DE AC04.94AL 85000.

Approved for public release; further dissemination unlimited. 
Issued by Sandia National Laboratories, operated for the United States Department of Energy by Sandia Corporation.

NOTICE: This report was prepared as an account of work sponsored by an agency of the United States Government. Neither the United States Government, nor any agency thereof, nor any of their employees, nor any of their contractors, subcontractors, or their employees, make any warranty, express or implied, or assume any legal liability or responsibility for the accuracy, completeness, or usefulness of any information, apparatus, product, or process disclosed, or represent that its use would not infringe privately owned rights. Reference herein to any specific commercial product, process, or service by trade name, trademark, manufacturer, or otherwise, does not necessarily constitute or imply its endorsement, recommendation, or favoring by the United States Government, any agency thereof, or any of their contractors or subcontractors. The views and opinions expressed herein do not necessarily state or reflect those of the United States Government, any agency thereof, or any of their contractors.

Printed in the United States of America. This report has been reproduced directly from the best available copy.

Available to DOE and DOE contractors from Office of Scientific and Technical Information

P.O. Box 62

Oak Ridge, TN 37831

Prices available from (703) 605-6000

Web site: http://www.ntis.gov/ordering.htm

Available to the public from

National Technical Information Service

U.S. Department of Commerce

5285 Port Royal Rd

Springfield, VA 22161

NTIS price codes

Printed copy: A03

Microfiche copy: A01

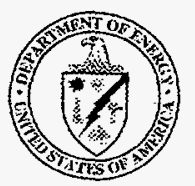




\section{DISCLAIMER}

Portions of this document may be illegible in electronic image products. Images are produced from the best available original document. 
SAND99-0099

Unlimited Release

Printed January 1999

\title{
Subsidence at the Weeks Island SPR Facility
}

\author{
Stephen J. Bauer \\ Underground Storage Technology Department \\ Sandia National Laboratories \\ P.O. Box 5800 \\ Albuquerque, NM 87185-0706
}

\begin{abstract}
The elevation change data measured at the Weeks Island SPR site over the last $16+$ years has been studied and analyzed. The subsidence rate is not constant with time and while the subsidence rate may have increased slightly during the past several years, recently the rate has increased more dramatically. The most recent increase comes at a time when the Strategic Petroleum Reserve (SPR) storage mine had been emptied of oil and was in the process of being refilled with brine. Damage to surface structures that has been observed during the past 12-18 months is attributed to the continued subsidence and differential subsidence across structures. The recent greater subsidence rates were unanticipated according to analysis results and will be used to aid further subsidence model development.
\end{abstract}




\section{Acknowledgements}

A thorough appreciation and understanding of elevation surveying and data quality was obtained from Eloy Solis of Jacobik \& Associates and Jim McHenry. The report benefited from these discussions. This report profited immensely through comments made by Darrell Munson and Brian Ehgartner. 


\section{Table of Contents}

\section{Page}

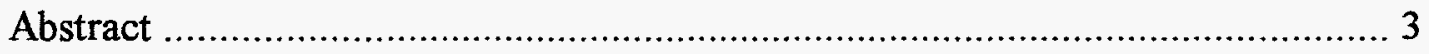

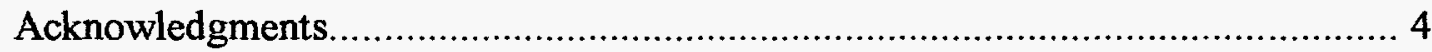

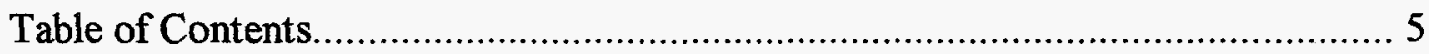

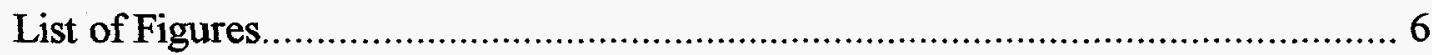

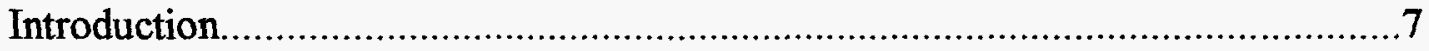

Procedures

Site Observations

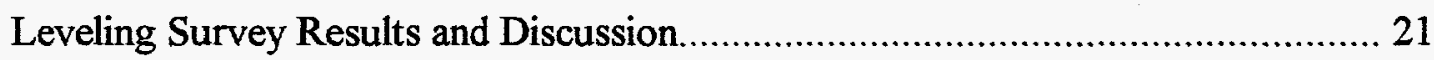

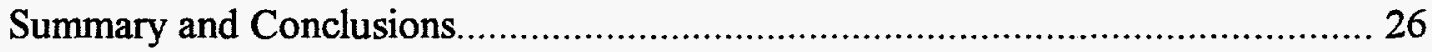

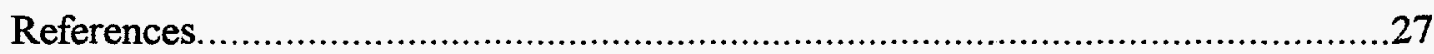

Appendix 1 Historic Elevation Measurements at Weeks Island...............................28

Appendix 2 Historic Subsidence Rates at Weeks Island........................................33

Appendix 3 Memo: S. J. Bauer to R. Myers dated 2/24/98, "Implications...............38 of Recent Subsidence Measurements at Weeks Island CORRECTED"

Distribution. 


\section{List of Figures}

Figure

Page

1. Site location map showing mine footprints and locations of newer subsidence monuments. 8

2a. Distant view of bent and sheared fiberglass panels on northeast side of hoist building....10

2b. Compressed nail hole features on northeast side of hoist building. 10

2c. Oblique view of bent and sheared fiberglass panels on northeast side of hoist building....11

2d. Close up view of sheared fiberglass sheathing and compressed nail hole features on northeast side of hoist building.

3a. Vertical crack in wall joining airlock room and hoist building (southwest side of hoist building).

3b. Horizontal foundation cracks on southwest side of hoist building...

3c. Vertical cracks in wall of airlock room on southwest side of hoist building..................12

3d. Stretched (extended) nail holes on southwest side of hoist building. .........................12

4. Horizontal separation between inner and outer concrete collars, and cracks in collars.....14

5. Bent stair rail, bent steel member and cracked steel joint, and buckled fiberglass panels inside hoist building.

6a. Vertical lift guide connected to massive horizontal (cracked) timber. Note vertical separation between inner collar and the top of the timber (about an inch). Also note lack of deformation in timber perpendicular to the cracked one.

6b. Vertical lift guide connected to massive horizontal (cracked) timber on opposing side to Figure 6a. Note similar vertical separation between inner collar and the top of the timber (about an inch). Also note localized deformation in corner of concrete collar

7a. Administration building area: cracking and horizontal displacement of brick fascia

7b. Administration building area: displacement of concrete walkway.

7c. Administration building area: cracking and displacement of concrete walkway 19

8a. Pipe support separated from pipe it had been supporting.

8b. and concrete abutment that has undergone rotation .

9. Restroom near shop: cracks in block work near door, shear cracks in tile work............20

10. Weeks Island subsidence rates $(\mathrm{ft} / \mathrm{yr})$ 11/83-2/90...........................................22

11 Weeks Island subsidence rates $(\mathrm{ft} / \mathrm{yr})$ 2/90-12/92 ..........................................22

12. Weeks Island subsidence rates $(\mathrm{ft} / \mathrm{yr})$ 2/92-2/95 ..............................................23

13. Weeks Island subsidence rates $(\mathrm{ft} / \mathrm{yr})$ 2/95-12/96 ...........................................23

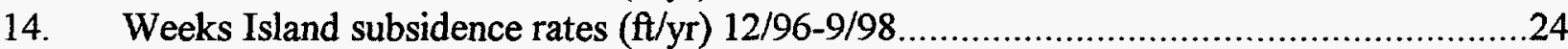




\section{Introduction}

The Weeks Island salt dome is located $23 \mathrm{~km}(14 \mathrm{mi})$ south of New Iberia, Louisiana, and is the central dome in the Five Islands chain, along with Belle Isle, Cote Blanche, Avery, and Jefferson Islands. All five have been mined because of their nearsurface salt, and their logistical advantage near the Gulf of Mexico and the Intracoastal Waterway. Belle Isle and Jefferson Island are now closed to mining because of deliberate and inadvertent flooding, respectively.

The sediment cover at Weeks Island consists of deltaic alluvium of the ancestral Mississippi River and is about $56 \mathrm{~m}(185 \mathrm{ft})$ thick over the top of salt. The water table conforms generally to sea level over the dome but fluctuates somewhat with topography and frequent torrential rains.

The Weeks Island Strategic Petroleum Reserve (SPR) facility is a former conventional two level room and pillar mine (Figure 1) purchased by the Department of Energy (DOE) from Morton Salt for the purpose of storing SPR oil. The mine was originally opened in 1902 and salt was extracted commercially until 1977, at which time Morton Salt developed a new mine immediately adjacent to the northwest while the older workings were converted for oil storage. The mine contained approximately 73 million barrels of crude oil from 1981 to 1996, at which time the removal of oil began.

Although not the subject of this report, products of local subsidence over the mine are sinkholes. A sinkhole measuring $11 \mathrm{~m}(36 \mathrm{ft})$ across and $9 \mathrm{~m}(30 \mathrm{ft})$ deep was first observed in the alluvium overlying the salt dome in May 1992. Based on initial surface appearance and subsequent reverse extrapolation of growth rates, it was already about a year old at discovery. A second and much smaller sinkhole was identified in early 1995 , nearly three years later. Their positions are located directly over the edges of the SPR oil storage chamber. The association of sinkholes with mines is well established. However, this occurrence suggested that groundwater influx into the mine was causing salt dissolution at depth, with associated collapse of soil at the surface (Neal, et al., 1998).

Beginning in January 1983, the subsidence monument elevations at the Weeks Island site have been surveyed 15 times. Bauer and Neal (1997) have most recently reported on the earlier survey data. Figure 1 is a base map of a portion of the Weeks Island site showing the footprint of the oil storage facilities and locations of a portion of the monuments. This report provides an update, which includes additional measurements completed in the past two years. The changes in elevation, the rates of subsidence, as well as projections of future elevation changes are presented. Of specific interest to the DOE at Weeks Island is the areal and localized subsidence rate of the surface. At Weeks Island, owing to general high elevations, absolute elevations are not of paramount importance.

At Weeks Island and SPR sites in general, elevation changes are primarily due to creep closure of caverns. General subsidence on the scale of the site or portions thereof is seen 


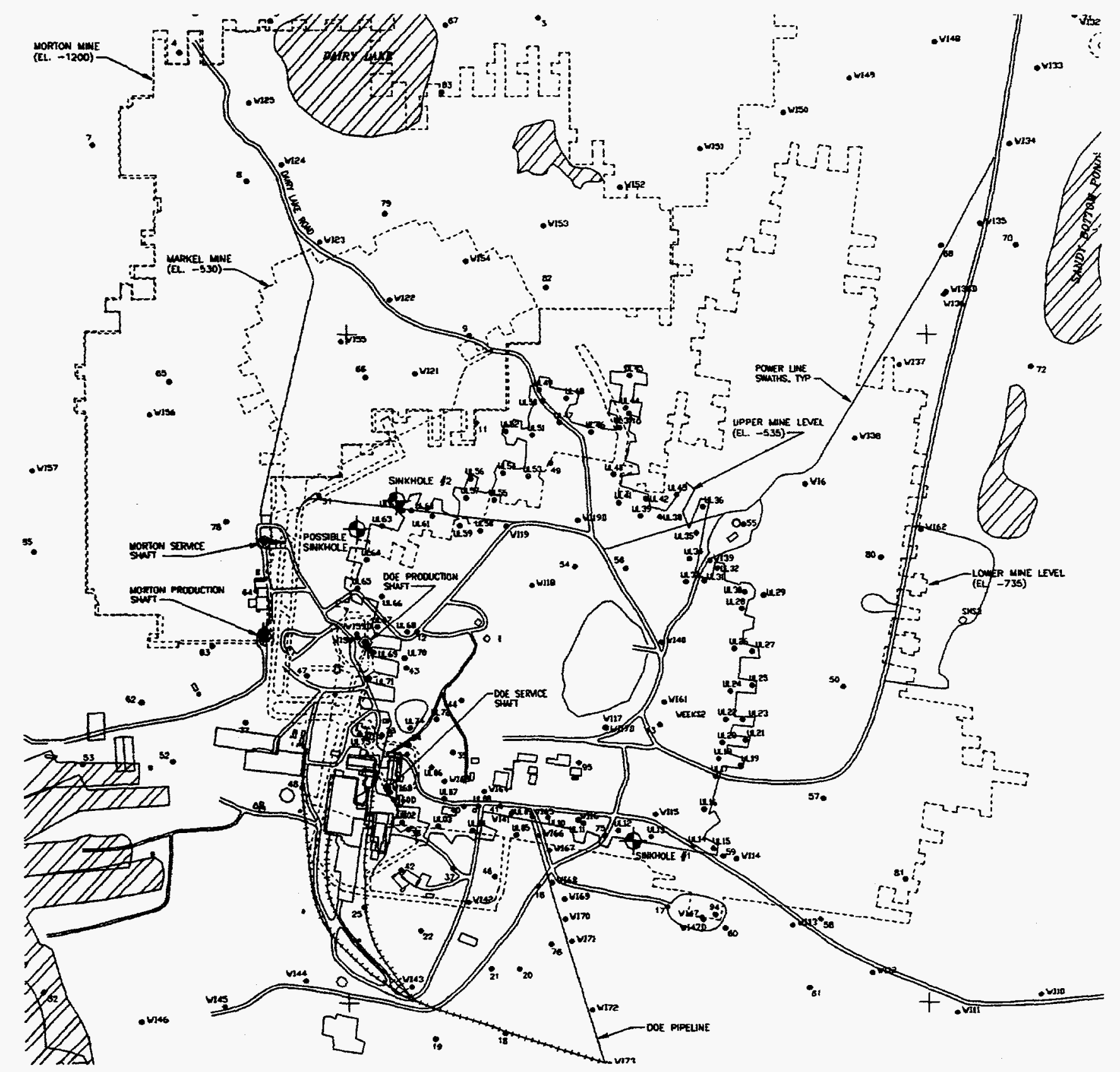

Figure 1. Site location map showing mine footprints and locations of newer subsidence monuments.

in the survey data taken. These subsidence measurements capture surface manifestations of creep closure of underground openings.

Subsidence is important because of general concerns for safety and site operations. Localized subsidence can adversely affect roads. Site facilities (electrical conduit, hoist equipment, valves, piping, etc.) could be damaged. Severe subsidence can impact future operations of the overall facility. The root cause (water leak into the mine) of localized 
subsidence at the Weeks Island facility has led to sinkhole development, emptying of the facility of oil, and planned decommissioning.

\section{Procedures}

Subsidence information is obtained in two ways, leveling surveys and visual observations. For the leveling surveys, elevation data represents the raw data. The measurements have been made at various time intervals; the current time interval is about 21 months. The most recent data set included 109 data points. The number of data points varies between measurements because loss of monuments occurs through destruction and damage. Three monuments recorded in the last survey were not included herein because the monuments were not located.

In practice, measurements of subsidence are difficult at best. At Weeks Island the reference is WI-1, installed before the February 1990 survey. WI-1 is located at the northeastern extremity of the survey network, outside the area affected by the oil storage and Morton mining; the elevation of WI-1 is verified at each survey. The elevation of Monument Disc 23v32 (the old baseline point) has in the past been surveyed and is currently used to verify the elevation of WI-1. Since 1988, the leveling surveys have been performed to Second-Order First-Class accuracy, with allowable vertical closure not to exceed $0.02 \mathrm{ft} / \mathrm{mile}^{0.5}\left(6 \mathrm{~mm} / \mathrm{km}^{0.5}\right)$. This means that for every mile long loop, the measurement must close to within .02 feet of the starting value. For loops less than a mile, the closure is accordingly smaller. Because WI-1 is so close to where measurements are made, the overall accuracy for measurements at the Weeks Island site is good. Furthermore, because survey loops are generally less than a mile, the accuracy is accordingly better than .02 feet. Osnes (1995) analyzed the surveying inaccuracies in the baseline data and found them to have a median value of about $.01 \mathrm{ft}$ and with approximately 95 per cent of the standard errors being less than $0.07 \mathrm{ft}$.

Subsidence over the large-scale area, (about three square miles) will likely be seen in the survey data taken. This type of subsidence captures gross effects of creep closure of underground openings. The surveys may also show precursors to localized subsidence.

Although observations from extensive surface traverses across the site are scheduled quarterly, localized subsidence and effects that manifest themselves as potential safety hazards are more likely to be seen by workers, as happened in 1998 . However, the detailed long term subsidence measurements provided by the surveys is important, especially because it permits the long term extrapolation of elevation changes into the future and provides a metric to evaluate numerical analyses.

\section{Site Observations}

The author has regularly visited Weeks Island other salt mine shafts in the Gulf Coast region. Unpublished observations have been made of subsidence related deformation of surface structures as well as deformations and maintenance/repair of 
surface facilities in the immediate vicinity of shafts. What follows are descriptions of observations of deformations of site facilities at the Weeks Island site. Observations of the nature described are not uncommon at salt mine facilities.

In mid September inspections of the Production Shaft building at Weeks Island were made in conjunction with other site related work. Observations of the exterior of the building show striking compressional features on the northeast side of the building (displaced nail holes and folded and faulted fiberglass sheeting) as shown in Figure 2. The deformation is accommodated on the southwest side of the building with extensile features as indicated by stretched nail holes in the fiberglass sheeting, horizontal cracks in the basal blocks of the building, and vertical cracks in the airlock room as shown in Figure 3. In addition, this room may be separating from the rest of the structure.

These observations in themselves represent superficial damage to the building and do not indicate any loss in function of either the shaft building or the adjacent airlock building.

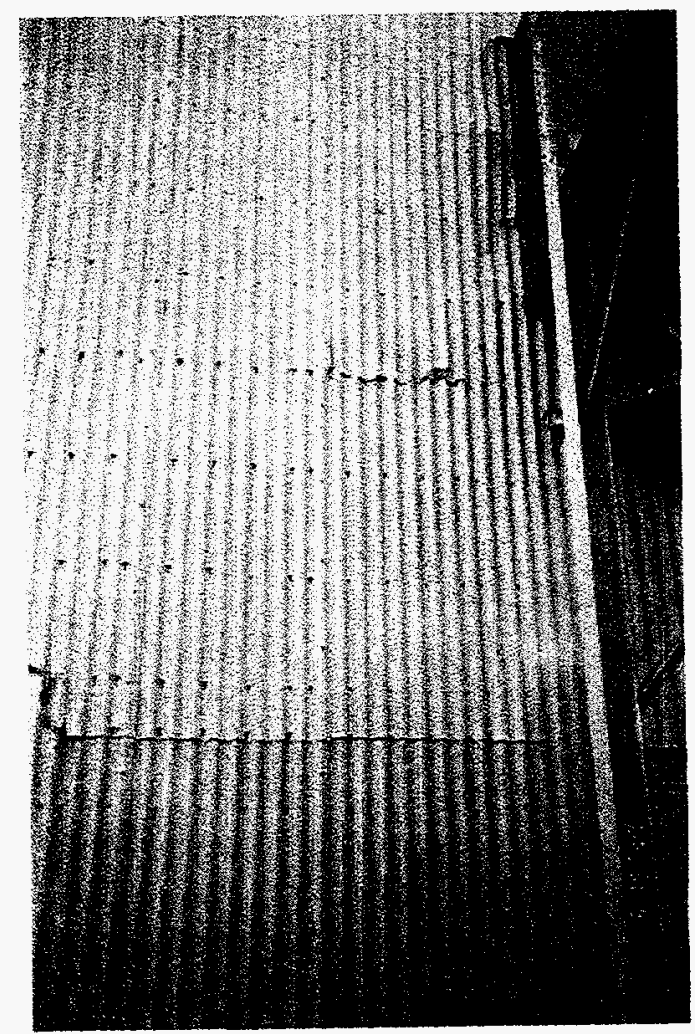

2a.

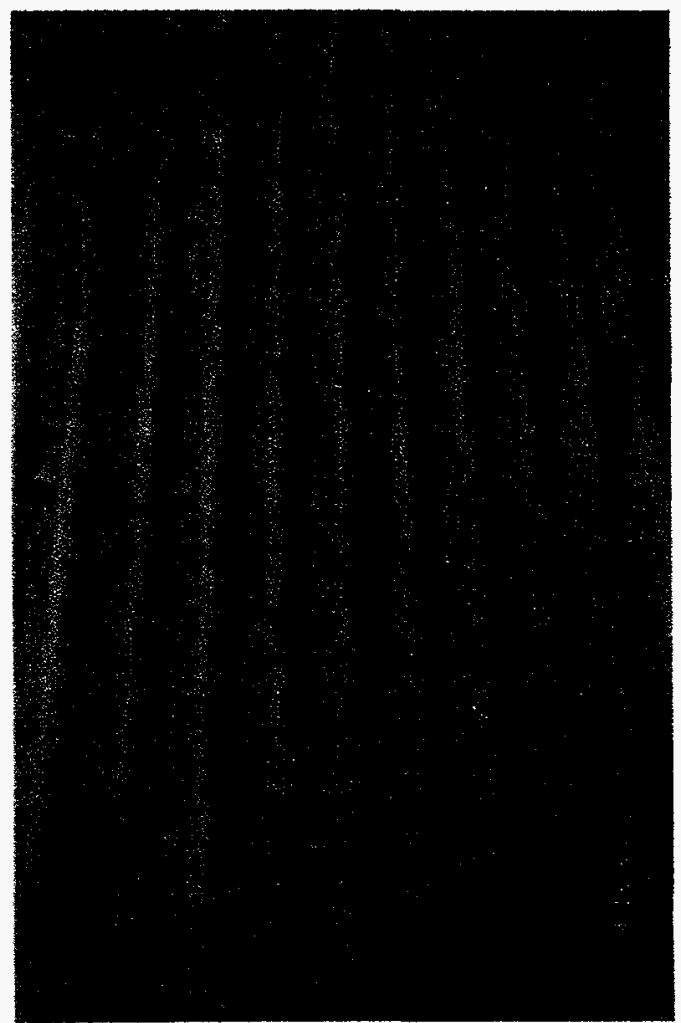

$2 \mathrm{~b}$.

Figure 2a. Distant view of bent and sheared fiberglass panels on northeast side of hoist building.

Figure $2 \mathrm{~b}$. Compressed nail hole features on northeast side of hoist building. 


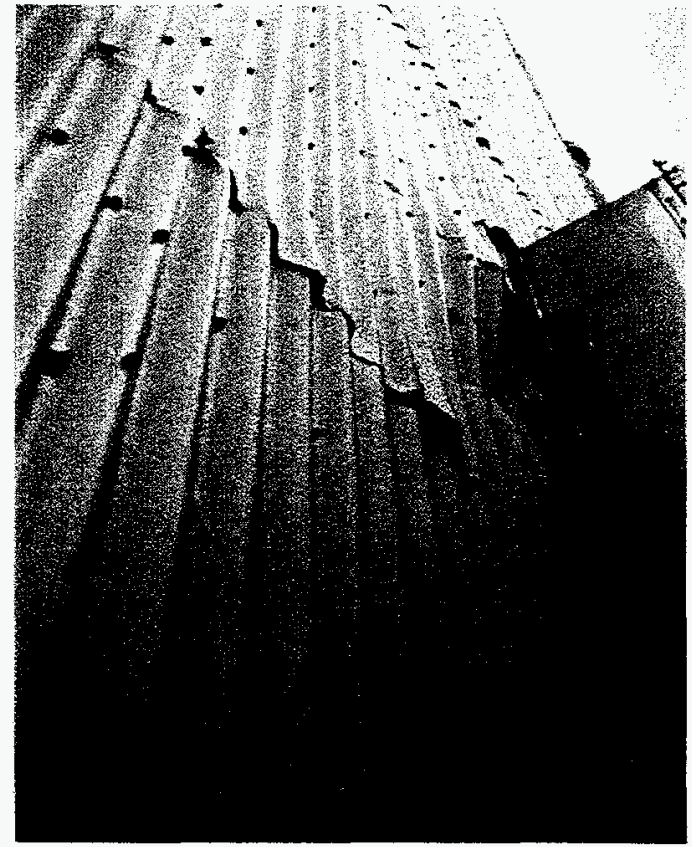

2c.

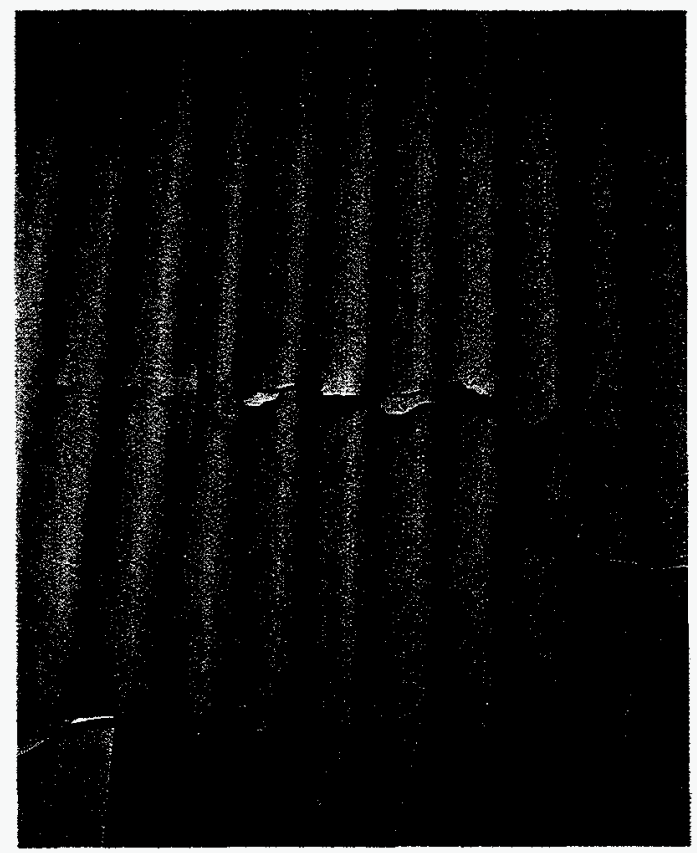

$2 d$.

Figure $2 c$. Oblique view of bent and sheared fiberglass panels on northeast side of hoist building.

Figure $2 \mathrm{~d}$. Close up view of sheared fiberglass sheathing and compressed nail hole features on northeast side of hoist building.

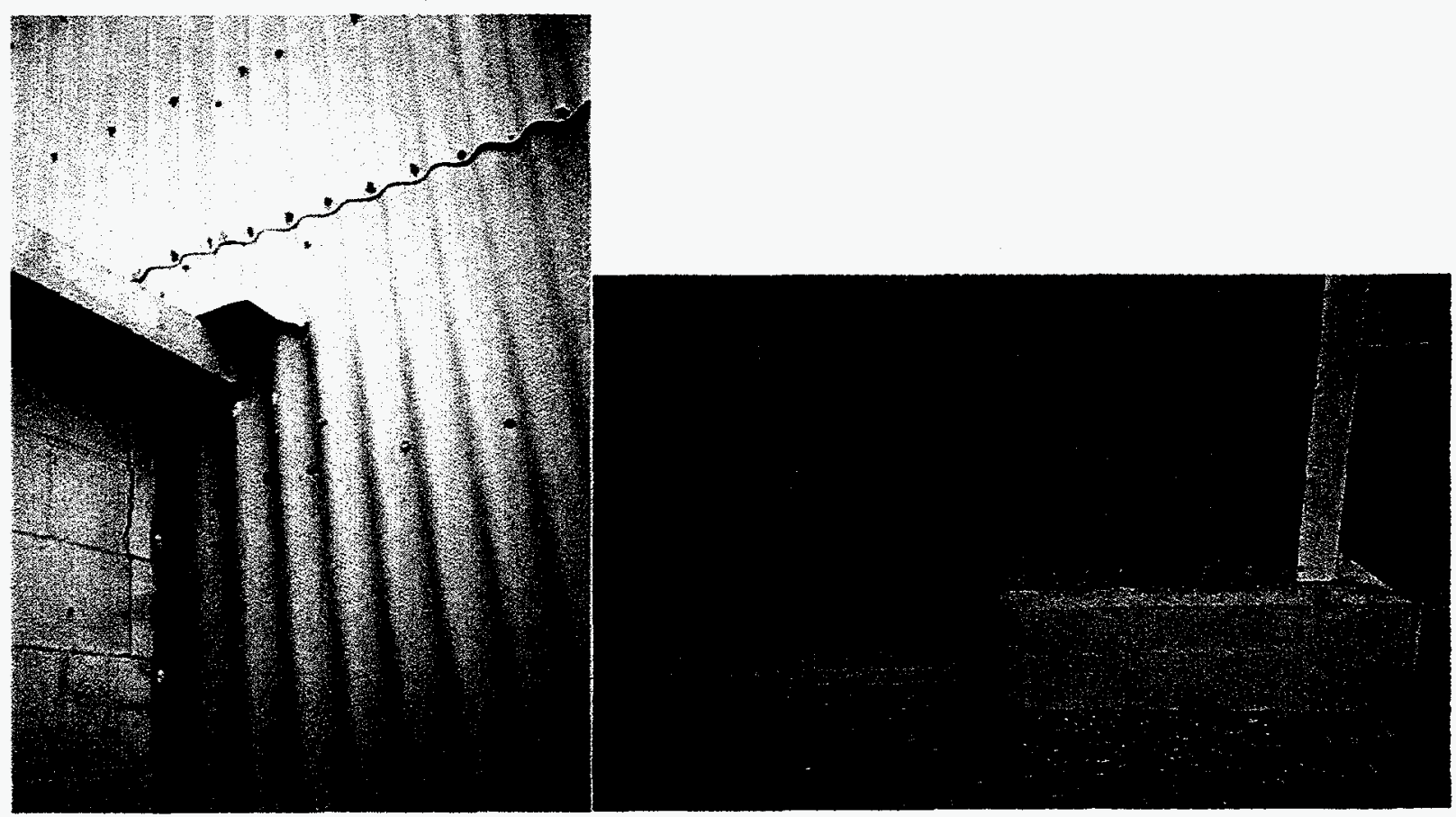

$3 a$.

$3 b$.

Figure 3a. Vertical crack in wall joining airlock room and hoist building (southwest side of hoist building).

Figure $3 b$. Horizontal foundation cracks on southwest side of hoist building. 


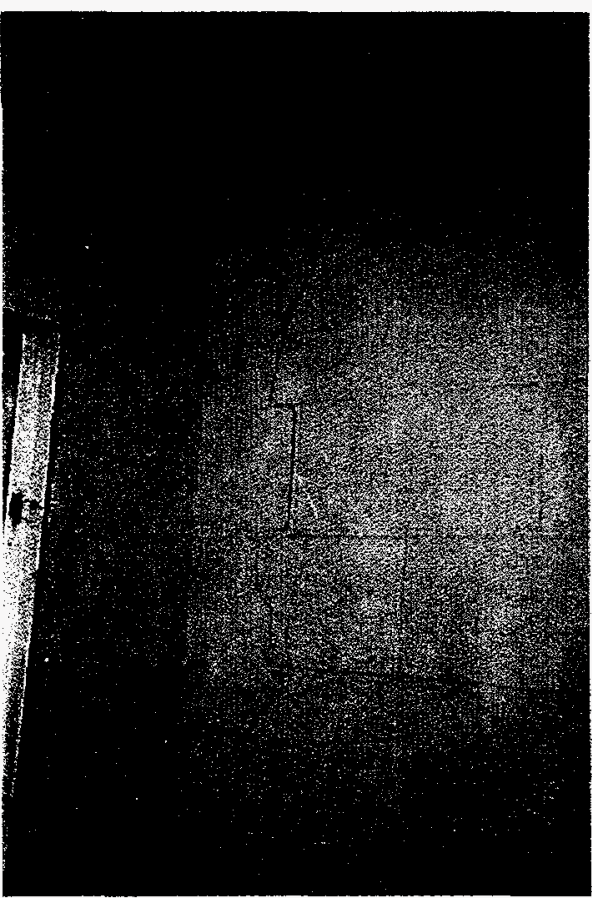

$3 c$.

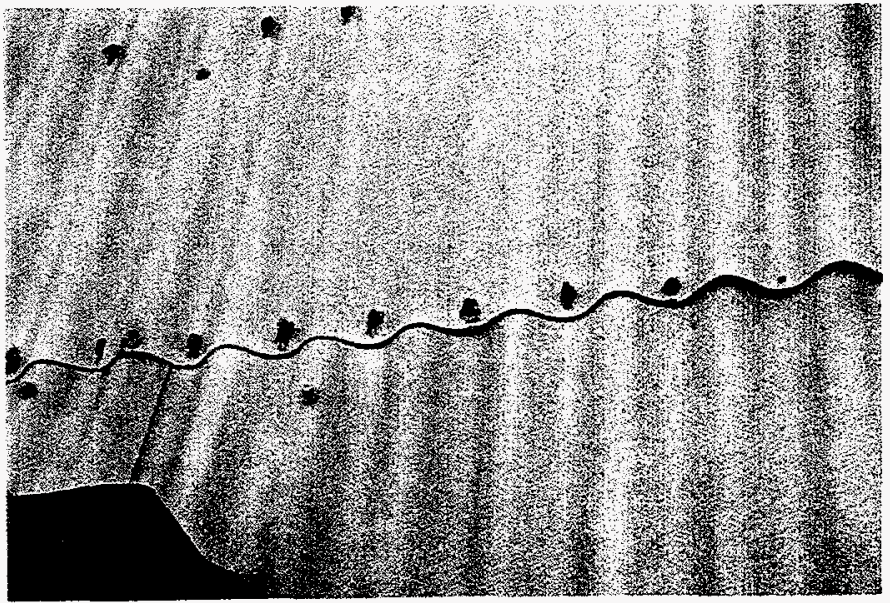

$3 d$.

Figure 3c. Vertical cracks in wall of airlock room on southwest side of hoist building. Figure 3d. Stretched (extended) nail holes on southwest side of hoist building.

From the above observations, it appears that the Production Shaft building is leaning from the southwest to the northeast towards the center of subsidence over the mine. Evidence of the origin of this leaning can be seen inside the building. The floor may be described as an inner collar that comes right up to the shaft edge, and an outer collar area. In places there is a horizontal separation between the two collar segments as evidenced by Figure 4 . Little to no relative vertical displacement was observed at this parted interface. The joint appeared to have been sealed at some time in the past with a bead of silicon joint compound. The joint now has more than half an inch of horizontal offset in places. Both the inner collar and outer collar are cracked, however, the outer collar appears to be much more heavily cracked.

The outer collar cracks first aroused workers attention more than a year ago, fostering a closer look at subsidence analyses (memo: Bauer and Linn to Berndsen dated 9/22/97). At that time it was determined that about 2 inches of differential subsidence had occurred across the building foundation during the past 40 years. Knowledge of the details of this differential subsidence and crack patterns in the pad could allow one to determine a cause and effect relationship between the subsidence and slab cracking.

The cracked concrete pad shows some vertical displacement immediately above the shaft liner where the inner collar appears to be lifted about an inch. This amount of displacement is consistent with the amount of cracking in the 3 to 4 foot thick concrete pad. The fiberglass panels inside the building are buckled in places, a stair rail is bent 
and a steel joint is cracked adjacent to a bent steel member (Figure 5). The function of all of these elements has been maintained. These observations are not unexpected given the pad cracking. Some leaning of the building frame has likely occurred, and certain nonstructural elements have deformed in response.

Deformation immediately around the shaft itself was also observed (Figure 6). The lift guides are tied to massive horizontal timbers through an intervening steel plate. Immediately below where the guides are tied to the massive horizontal timber members there is a horizontal crack in each of the horizontal timber members. The crack in each opposing member appears widest (about $0.5^{6}$ ) at the center of the beam; the crack on both timbers dies out at the ends. It appears that the timbers are being pulled upward from where they are fastened to the vertical guides. It is adjacent to the cracked horizontal timbers that the inner collar appears to be lifted off the timbers about an inch. One corner of the inner collar had localized deformation in the form of cracking and shear displacement. No cracks were observed in either of the cross timbers, which run perpendicular to those connected to the lift guides. Also, it is important to note that no cracks were observed in the vertical lift guide timbers. The function of the system is again retained.

The very top of the shaft liner was examined with a fairly powerful flashlight while peering in from the inner collar. No cracks or other signs of degradation were visible in the shaft liner from this vantage point.

From the above observations it appears that the hoist structure is leaning from the southwest to the northeast as a result of some sort of differential settlement in the piling support for the structure. The hoist building is quite tall. This leaning has caused the exposed vertical structures to bend under gravitational loads, causing the shaft lift guides to pull up on the inner collar and horizontal timbers (causing cracking). The outer collar is cracking quite a bit because of underlying movements (concrete is weak in tension). The observed twisting of steel members and bending of inner and outer building sheathing is clearly their response to the deformation of structural elements to which they are attached. 


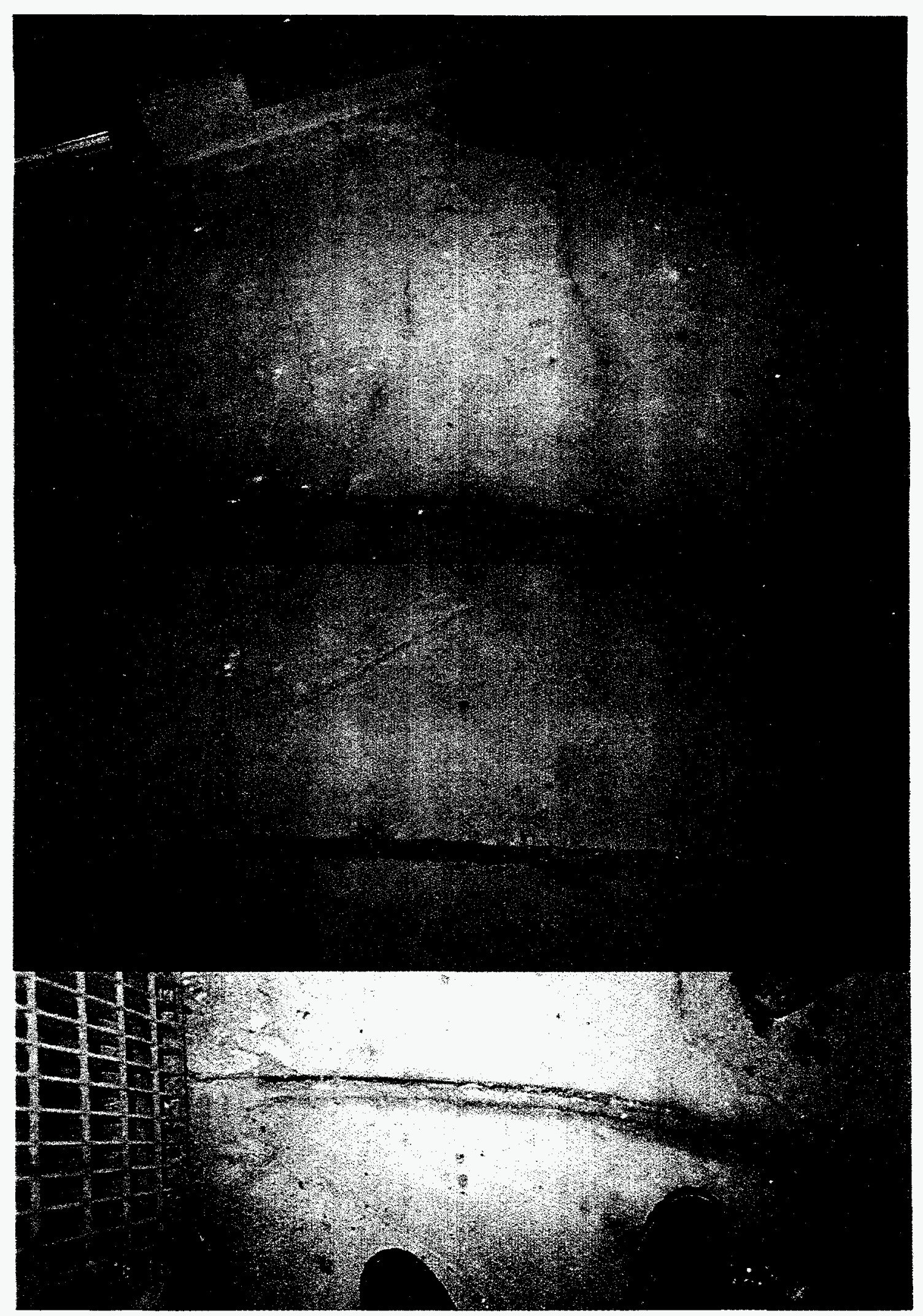

Figure 4. Horizontal separation between inner and outer concrete collars, and cracks in collars inside Production Shaft hoist building. 


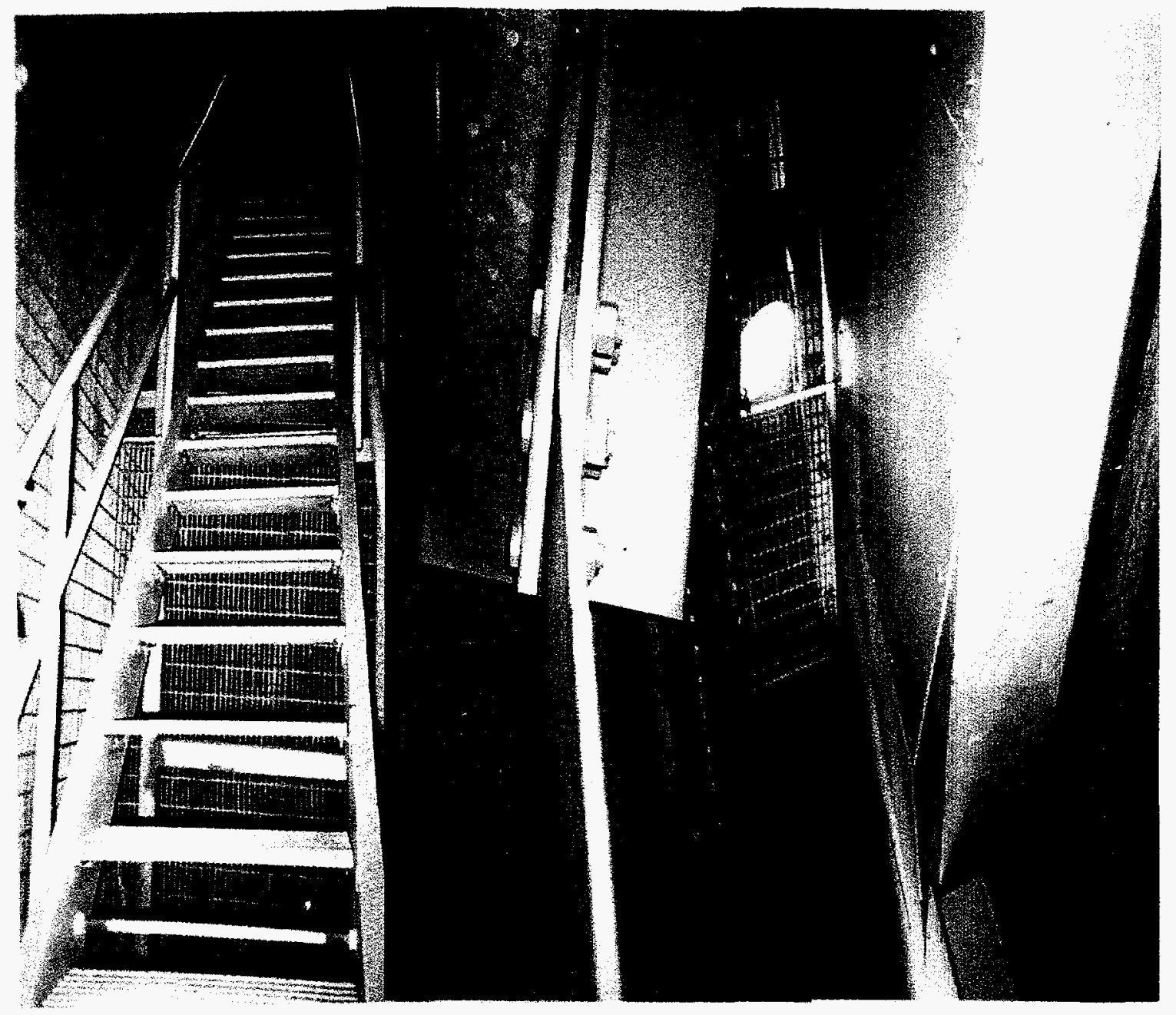

Figure 5. Bent stair rail, bent steel member and cracked steel joint, and buckled fiberglass panels inside hoist building. 

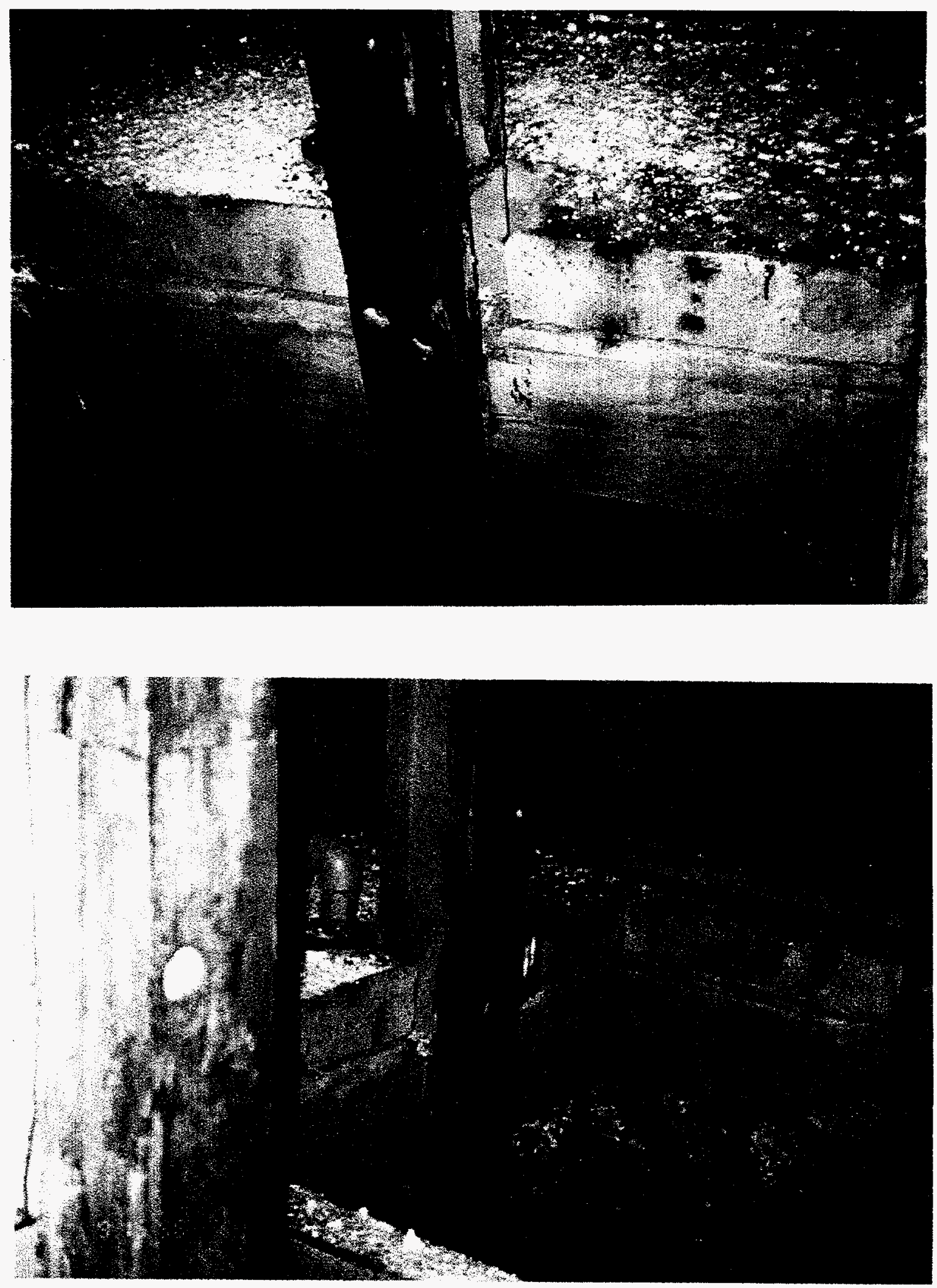

Figure 6a. Vertical lift guide connected to massive horizontal (cracked) timber. Note vertical separation between inner collar and the top of the timber (about an inch). Also note lack of deformation in timber perpendicular to the cracked one. 


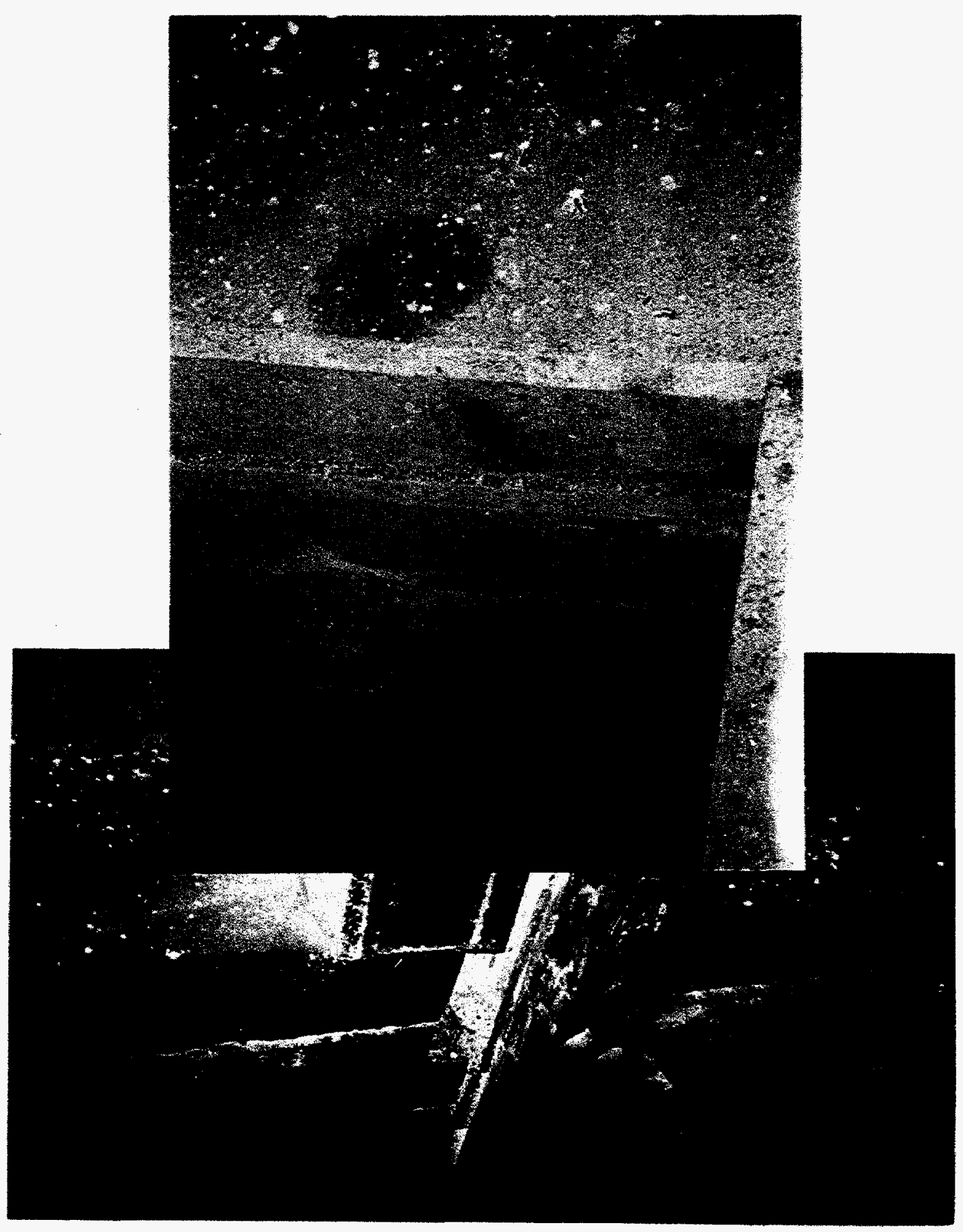

Figure 6b. Vertical lift guide connected to massive horizontal (cracked) timber on opposing side to Figure 6a. Note similar vertical separation between inner collar and the top of the timber (about an inch). Also note localized deformation in corner of concrete collar. 
Previous work (Bauer and Linn, 1997) has been cited dictating a potential cause and effect relationship between subsidence and cracking in the concrete observed about a year ago. The direction of leaning of the hoist building is consistent with subsidence gradient from a direction of less subsidence on the mine edge (west side of hoist building) to more subsidence (east side of hoist building), directly over the mine.

As stated above, phenomena of this nature are not uncommon in the vicinity of shafts at salt mines.

During a recent quarterly surface inspection, evidence of possible effects of subsidence upon other DOE structures was observed (Bauer, 1998). Again these observed cracks in buildings and displacements in concrete walkways are likely the result of differential subsidence at the site.

Some observations were made inside the DOE main area, that are indicative of damage to surface facilities, which are also likely the result of surface subsidence. The brick fascia on the corners of the administration building has vertical cracks and attendant displacement. The concrete walkway on the south of the administration building and the one to the west of the old guard house has been cracked and displaced (Figure 7). A pipe support is sinking away from the pipe it is supposed to be supporting and a concrete abutment is rotating (Figure 8). There are cracks in the block work inside and outside of the door to the restroom next to the shop and shear cracks can be found in the tile work in the wall of the restroom (Figure 9). These observations should be expected in facilities which overlie ground across which considerable differential subsidence has been documented. The function of these facilities has not been effected by the deformations present. Further, the observations have led to an increased awareness of subsidence and its effects on surface facilities, an increase in the frequency of subsidence measurements, and a more aggressive attitude towards brine refill of the mine. 


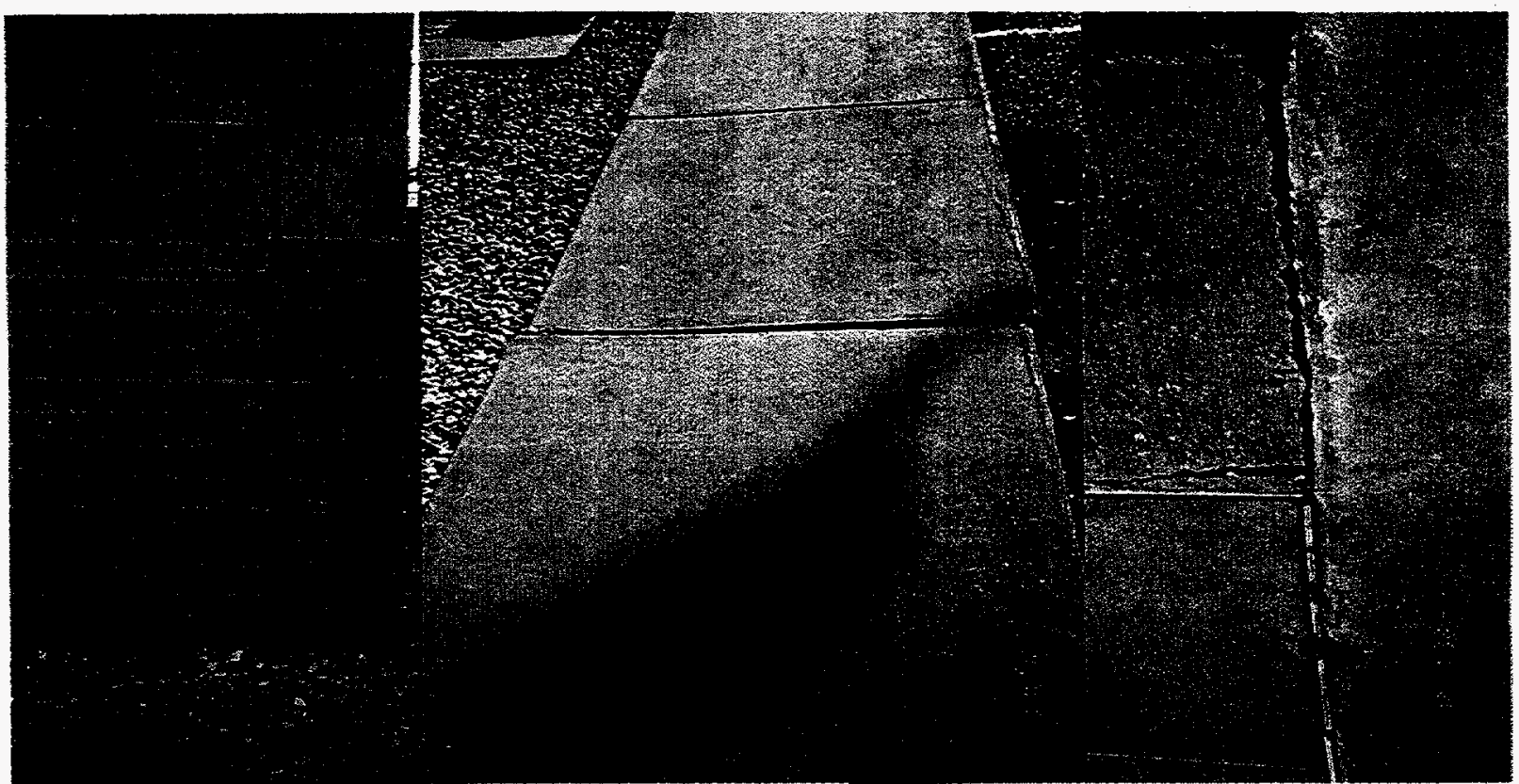

$7 a$.

$7 \mathrm{~b}$.

7c.

Figure 7. Administration building area: (a) cracking and horizontal displacement of brick fascia and (b) displacement of concrete walkway and (c) cracking and displacement of concrete walkway.

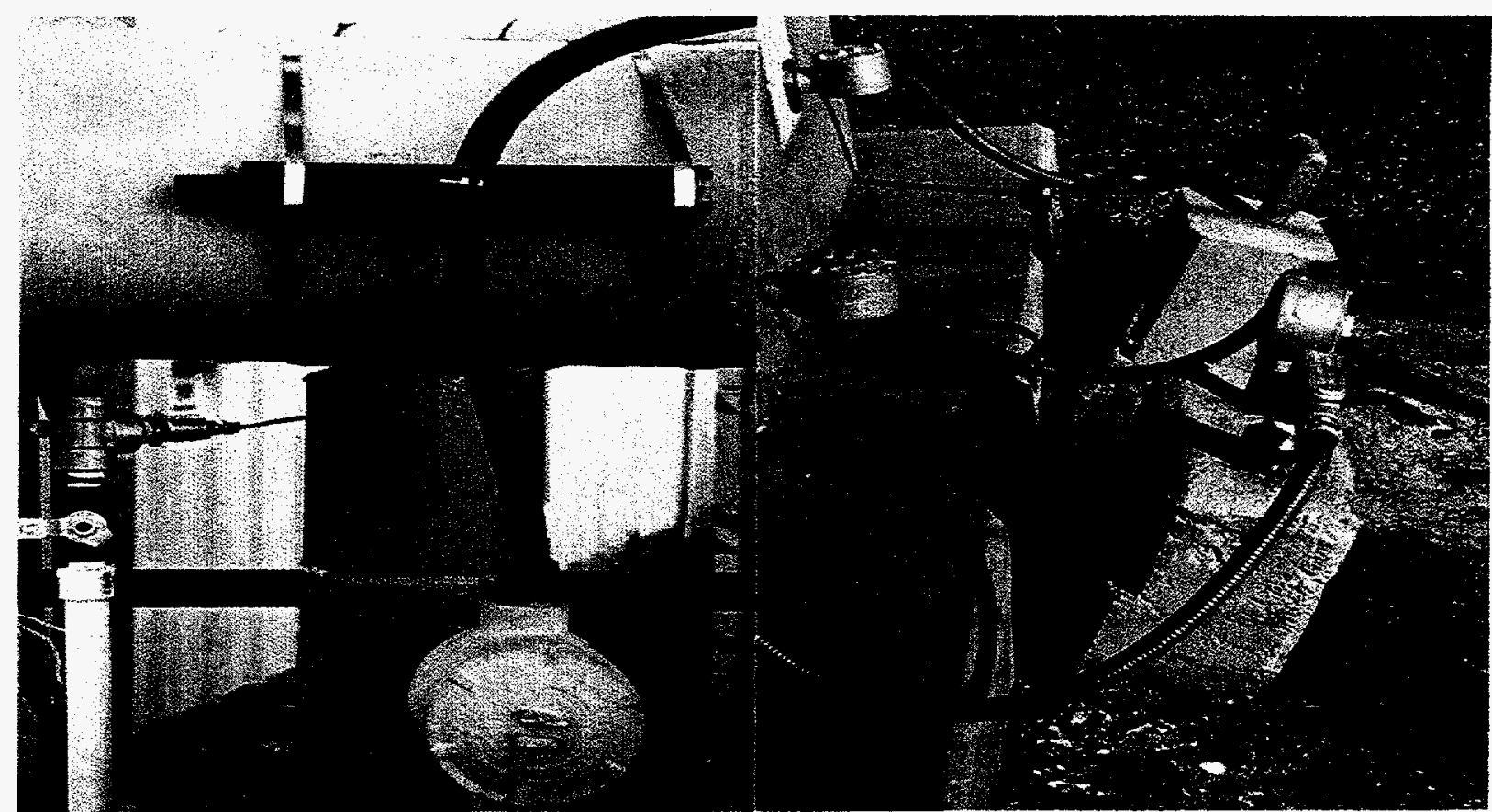

8 a.

$8 b$.

Figure 8. (a) pipe support separated from pipe it had been supporting, (b) concrete abutment that has undergone rotation. 


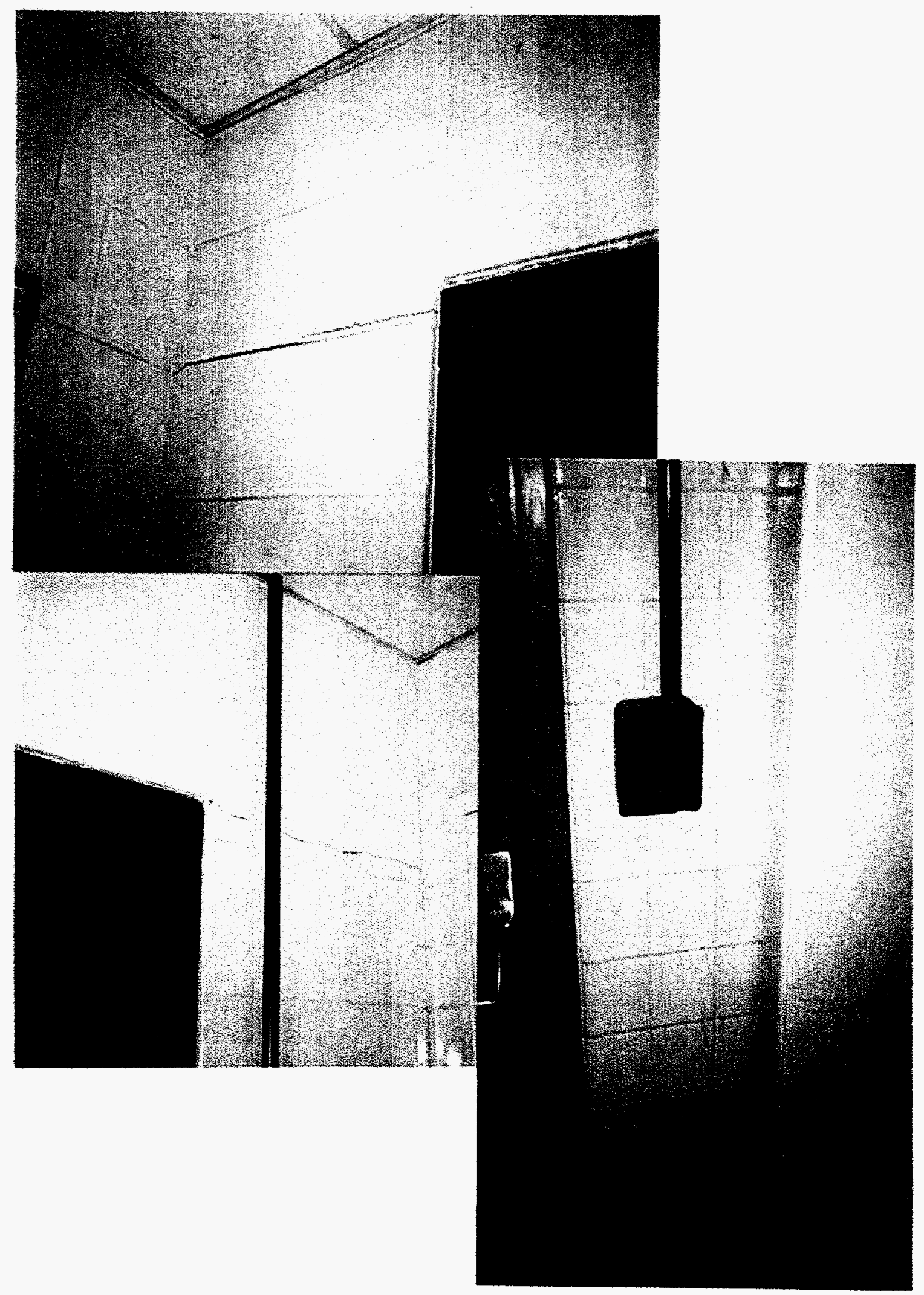

Figure 9. Restroom near shop: cracks in block work near door, shear cracks in tile work. 


\section{Leveling Survey Results and Discussion}

The results of measurements of elevation data since May of 1983 are given in Appendix 1. At Weeks Island the absolute values of vertical displacement are of interest, but more important in signaling potential problems are the subsidence rates and changes in subsidence rates with time. Subsidence rate data are displayed in Appendix 2 and Figures 10-14. The rates reported are annualized rates (ft/yr) for the time interval between measurements, and the figures presented consider longer time periods than a single measurement interval. Subsidence rates are due to creep closure of the underlying oil storage facility and the adjacent Morton Mine creep closure.

From 1983-1990 the area surveyed was relatively small (about a quarter of a square mile) compared to the DOE property boundary, and contained only about twenty measurement stations (Figure 10). The subsidence rate averaged between 0 and $0.1 \mathrm{ft} / \mathrm{yr}$ during this time period, but only one station was located over the center of the mine.

The survey station array has been gradually increased since 1990 to currently include over a hundred stations (109 in 1998), some of which are located over the middle of the DOE facility. Each year some stations are not found, destroyed, or buried.

Figure 11 presents subsidence rates for the entire nearly three square mile area currently studied for the 1990-1992 time period. The extended array encompasses the DOE facility, a portion of the Morton mine facility to the northwest as well as more stable areas to the east and southeast of the DOE facility. An important observation made consistent with these data is the continued rise of the Weeks Island salt dome. The rate of uplift is about $0.01 \mathrm{ft} / \mathrm{yr}$. Also evident for the first time with these measurements are the greater rates of subsidence over the DOE mine area and rates over the Morton facility. These greater rates are recorded for the first time possibly because of the increased number of monuments added in this area and because of the greater accuracy ascribed to the survey.

From 1992 to 1995 (Figure 12) the subsidence rates appear very similar to the previous time period with the exception that a localized increased subsidence rate is observed in the northern part of the DOE facility area. This northern area "anomaly" disappears in the 1995-1996 time frame (Figure 13). The observed rates over the DOE and Morton facilities persist, with an increase up to $0.2-0.3 \mathrm{ft} / \mathrm{yr}$ range over the DOE facility reflecting the drawdown of the mine which started in November 1995. 
Weeks Island Subsidence Rate (ft/yr) 11/83-2/90
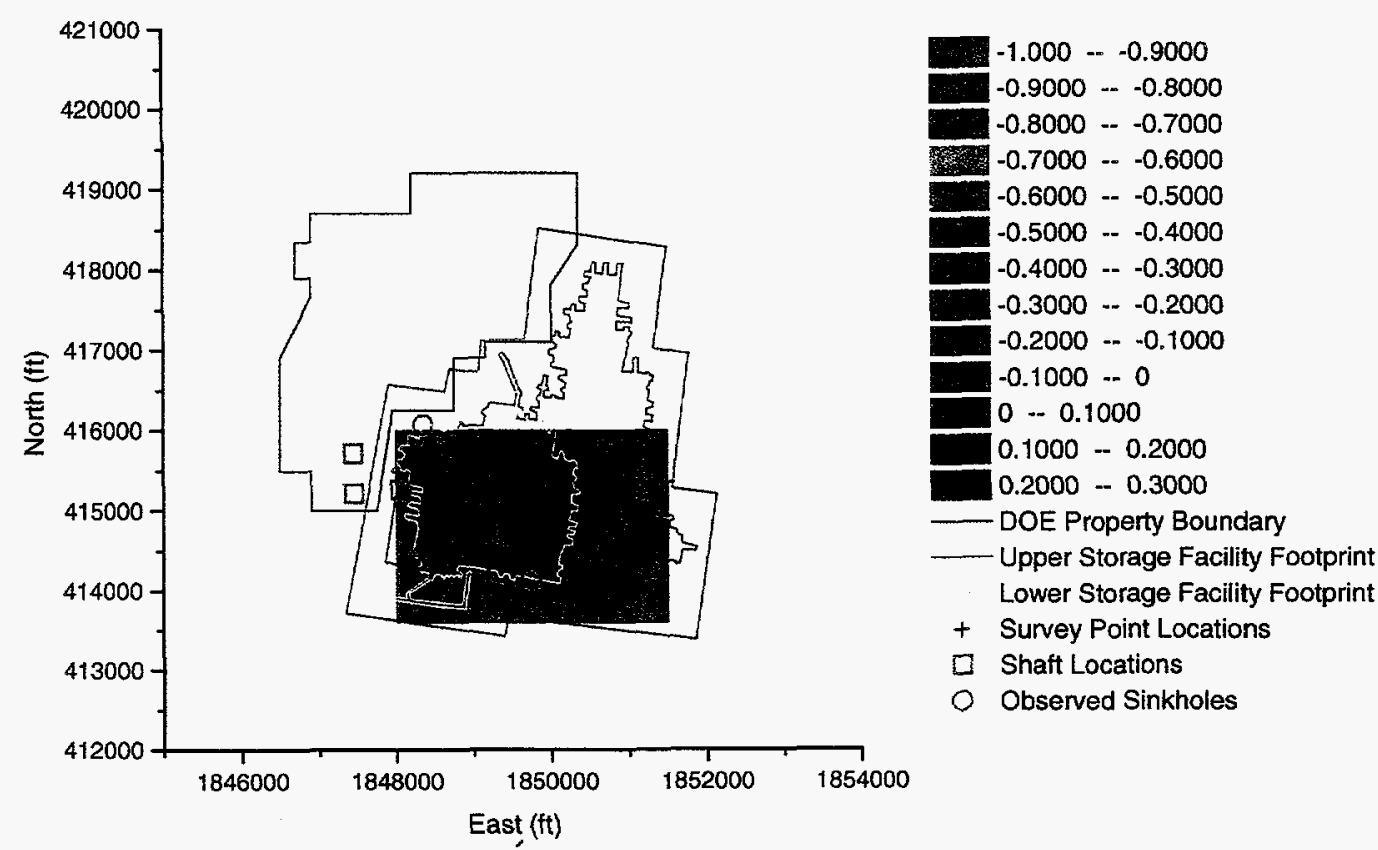

Figure 10. Weeks Island subsidence rates (ft/yr) 11/83-2/90.

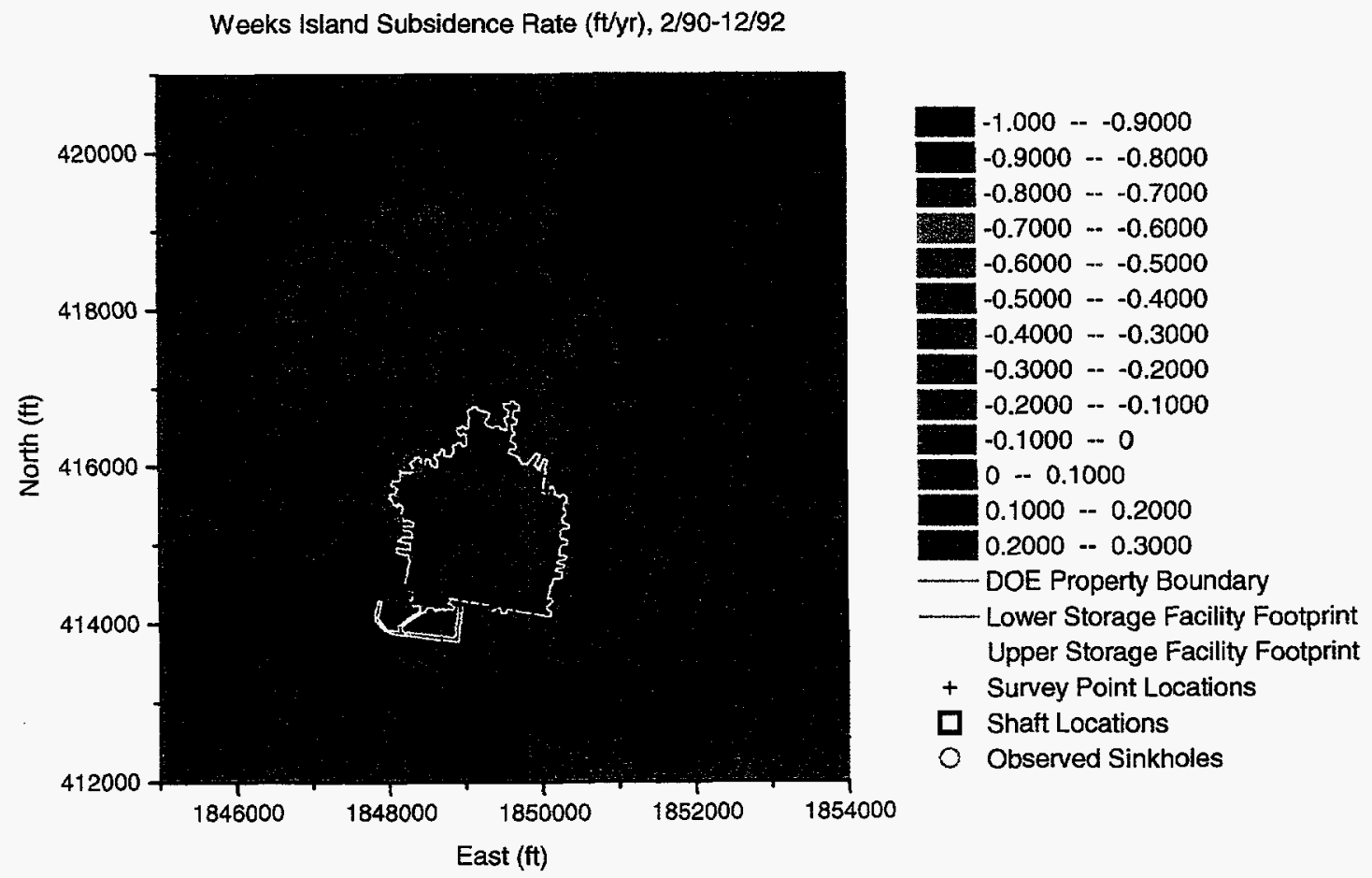

Figure 11. Weeks Island subsidence rates (ft/yr) 2/90-12/92. 


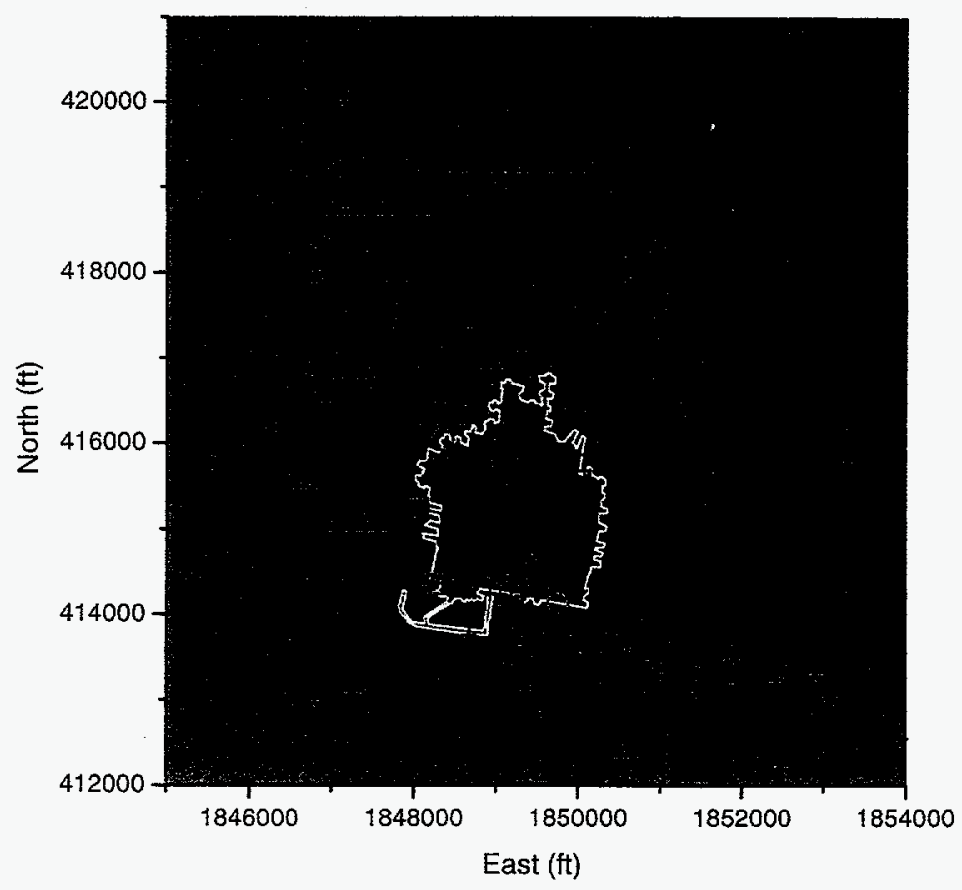

$-1.000--0.9000$

$-0.9000--0.8000$

$-0.8000--0.7000$

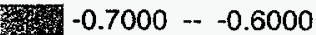

$-0.6000--0.5000$

$-0.5000--0.4000$

$-0.4000--0.3000$

$-0.3000---0.2000$

$-0.2000--0.1000$

$-0.1000-0$

$0-0.1000$

$0.1000-0.2000$

$0.2000--0.3000$

DOE Property Boundary

Lower Storage Facility Footprint Upper Storage Facility Footprint

+ Survey Point Locations

$\square$ Shaft Locations

O Observed Sinkholes

Figure 12. Weeks Island subsidence rates (ft/yr) 2/92-2/95.

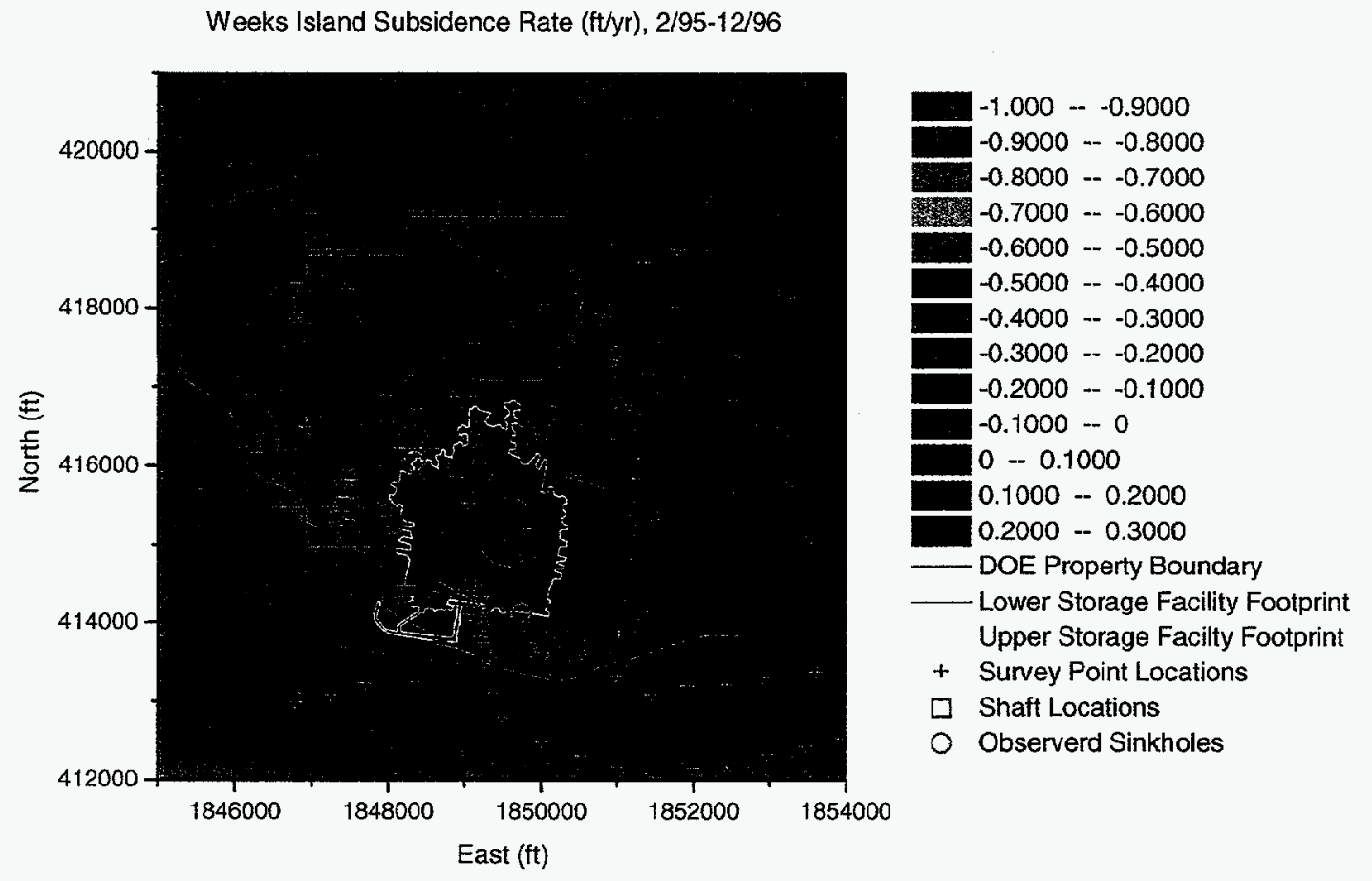

Figure 13. Weeks Island subsidence rates (ft/yr) 2/95-12/96. 
Between $12 / 96$ and $9 / 98$ the subsidence rates over the DOE facility increased markedly (Figure 14). Maximum subsidence rates are near $1 \mathrm{ft} /$ year (near subsidence monuments Weeks 2 and WI-61- see red contour area on Figure 14). Subsidence rate increases were observed for most of the DOE facility area, in the 0.3 to $0.5 \mathrm{ft} / \mathrm{yr}$ range. In summary, local rates increased by a factor of up to four to five, whereas overall rates increased by a factor of two to three. Subsidence rate increases of two to three are also observed to the northwest, over the Morton facility. The white triangles in Figure 14 represent stations that experienced a factor of three or greater increase in subsidence rate. In looking at the figure one must be careful to understand the relative amount of the increase in context with the absolute amount of increase. The high rate increases found over much of the

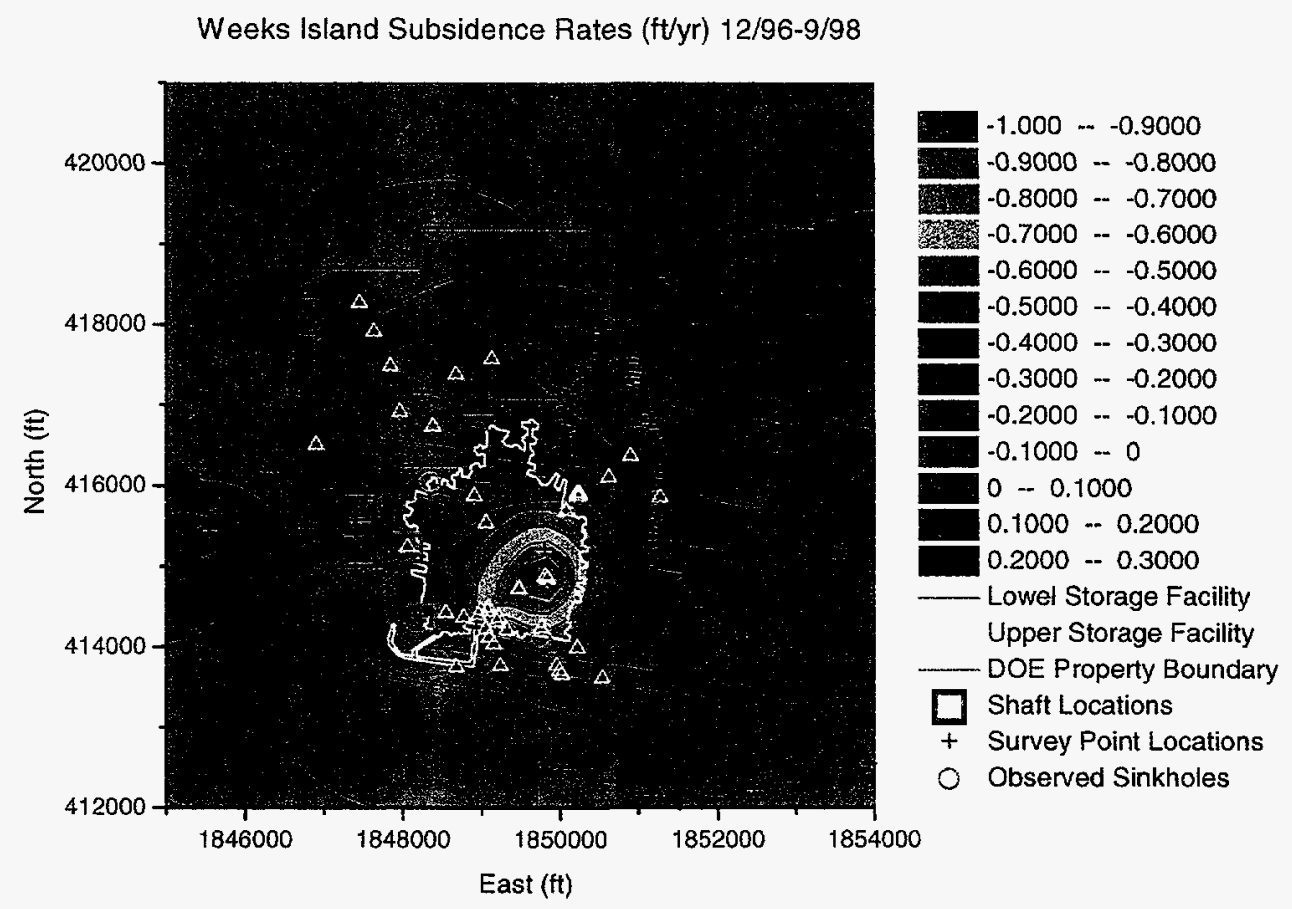

Figure 14. Weeks Island subsidence rates (ft/yr) 12/96-9/98.

DOE and Morton facilities are potentially due to emptying the mine and may in part be the result of the continued mining or an increase in extraction in the Morton mine.

The recent increase in subsidence rates is consistent with the data collected local to Sinkhole \#1 (Appendix 3) for the time period of early-mid 1997. That data showed that subsidence near Sinkhole \#1 was consistent with observed subsidence over other areas of the mine. At that time (prior to the most recent subsidence data), the increase in rates observed was believed attributable to the emptying of the mine of oil. For the recent measurements, increased subsidence is observed at the Weeks Island site predominantly over the oil storage facility and Morton facilities. The subsidence rate change over the 
DOE facility is likely due to increased salt creep mine closure. This increase in mine closure rate is likely the result of the stress state and its changes in the mine and storage facility with time.

Since the mine was filled with oil in 1981 , no access has been gained into the oil storage areas. Any thoughts on the causes for the observed subsidence patterns are guided by a combination of measurements and mechanical analysis. Large unknowns exist pertaining to what has physically happened in the DOE mine. Slabbing and rockfall have been postulated (Ehgartner, 1998). Mining has continued at the Morton facility, and the extraction history there of course affects the subsidence over the DOE facility (Ehgartner, 1998).

At the DOE facility, the stress state is determined by the facility depth, internal geometry, in situ stress, fill condition (oil filled, or partially oil filled, empty, brine filled or partially brine filled), and pillar condition with time. The depth and in situ stress state have remained relatively constant through the past 20 year study period. The internal geometry has also remained relatively constant, once DOE assumed ownership of the facility. The fill condition has changed with time. The mine was initially empty in 1982 , was filled by 1983 and remained filled through 1996. At that time the mine emptying began and took 9 months to complete.

The stress state change during the emptying varies with mine depth and is determined by the "head" of oil back pressure when oil filled (or partially filled). Since that time (emptying) the mine has been at various levels of brine refill during the skimming phases, and again the stress state change during the brine refill varies with mine depth and is determined by the "head" of brine back pressure when brine filled (or partially filled). These stress changes would have resulted in a $60 \%$ subsidence rate increase (Hoffman,1994) and cannot fully account for the recent observed subsidence rate change. However, Hoffman's work does show agreement between calculated results and the 1996 subsidence data.

The brine used for refill has been about $80 \%$ saturated. This brine quality has probably facilitated some dissolution of the mine surfaces. If much of this dissolution took place on pillars, decreasing their cross sectional areas would have caused a local increase in the stress state. The fairly uniform distribution of high rates of subsidence rate increase (Figure 14) indicates that if this is the operable mechanism, then the dissolution and consequent deformation are widespread. This and the possibility that the pillars could have experienced some damage when the oil was withdrawn are the subject of ongoing analyses (Ehgartner, 1998). 


\section{Summary and Conclusions}

The elevation change data measured at the Weeks Island SPR site over the last $16+$ years has been studied and analyzed. The subsidence rate has increased slightly during the past several, recently the rate has increased more dramatically. The recent increase comes at a time when the Strategic Petroleum Reserve (SPR) storage mine had been emptied of oil and was in the process of being refilled with brine.

Damage to surface structures that has been observed during the past $12-18$ months is attributed to the continued subsidence and differential subsidence across structures. This type of deformation is not uncommon at other shaft building facilities above Gulf Coast salt mines. Damage of this type should be anticipated at SPR facilities wherever differential subsidence of sufficient magnitude across a facility element may occur. None of the observed damage has caused loss of function of the various facilities.

This report points to a continued need to routinely collect a complete set of elevation data at SPR facilities. The data collected has provided information to the project that was unanticipated by previous analyses. Thus, the data can be used not only to constrain and compare with future analyses, but also as an important diagnostic tool. 


\section{References}

Bauer, S. J., 1998, Memo to G. Berndsen, September 20, 1998. "Recent Observations at Weeks Island Production Shaft", Dept. 6113, MS0706, Sandia National Laboratories, Albuquerque, NM 87185-0706.

Bauer, S. J., 1998, Memo to G. Berndsen, September 20, 1998. "Quarterly Surface Inspection of Weeks Island Mine Perimeter", Dept. 6113, MS0706, Sandia National Laboratories, Albuquerque, NM 87185-0706.

Bauer, S. J. and J. Linn, 1998, Memo to G. Berndsen, September 25, 1998. "Preliminary look at Weeks Island Subsidence", Dept. 6113, MS0706, Sandia National Laboratories, Albuquerque, NM 87185-0706.

Bauer, S. J. and J. Neal, 1997, Memo to G. Berndsen, March 1997. "Analysis of subsidence data for the Weeks Island Site." Sandia National Laboratories, Albuquerque, NM 87185-0706.

Ehgartner, B., 1998, personal communication, Dept. 6113, MS0706, Sandia National Laboratories, Albuquerque, NM 87185-0706.

Hoffman, E., 1994, Memo to J. K. Linn, March 28, 1994. "Investigation of pressurization and Draw Down of the Weeks Island Oil Storage Facility." Sandia National Laboratories, Albuquerque, NM 87185-0706.

Neal, J. T., S. J. Bauer and B. L. Ehgartner, 1998,"Mine-induced Sinkholes Over the U. S. Strategic Petroleum Reserve (SPR) Storage Facility at Weeks Island, Louisiana: Geologic Causes and Effects", Land Subsidence Case Studies and Current Research; Proceedings of the Dr. Joseph F. Poland Symposium edited by J. W. Borchers.

Osnes, J., 1995, "Update to subsidence analyses of SPR site for fiscal years 1993 and 1994”, Re/Spec Topical Report RSI-0590 for DynMcdermott. 


\section{Appendix 1}

Historic Elevation Measurements at Weeks Island 


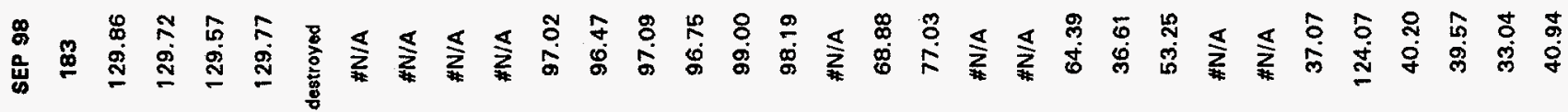

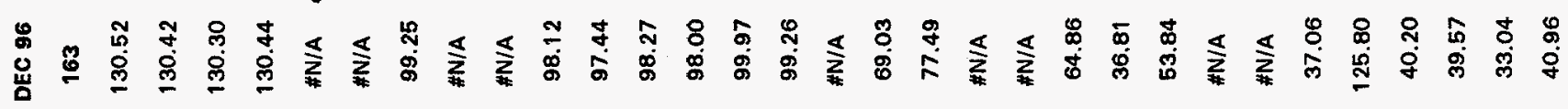

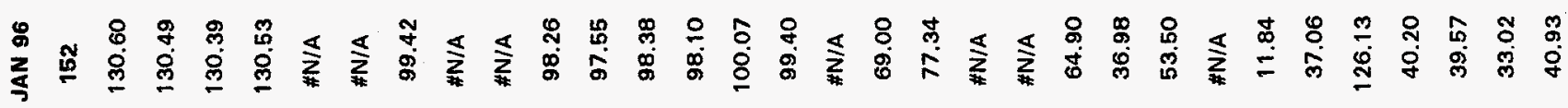

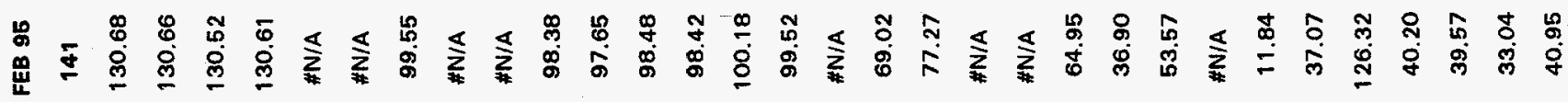

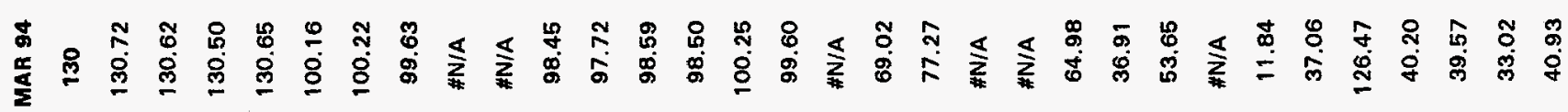

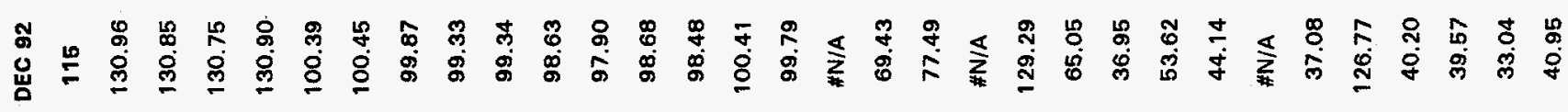

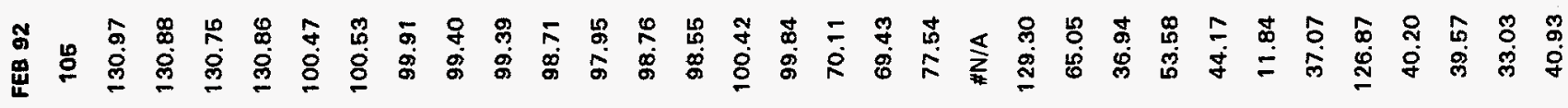

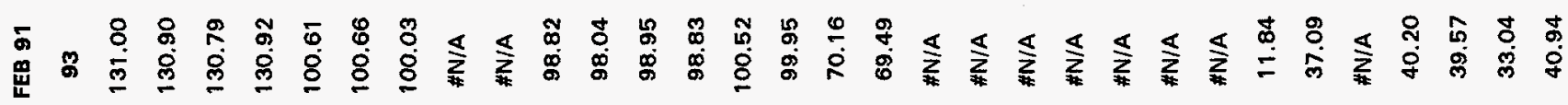

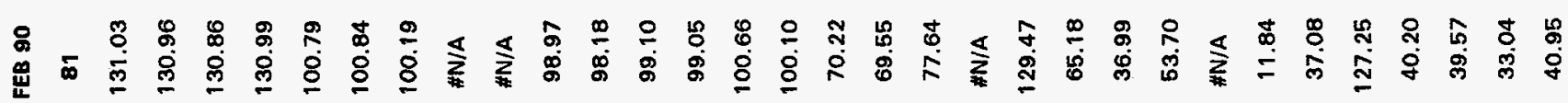

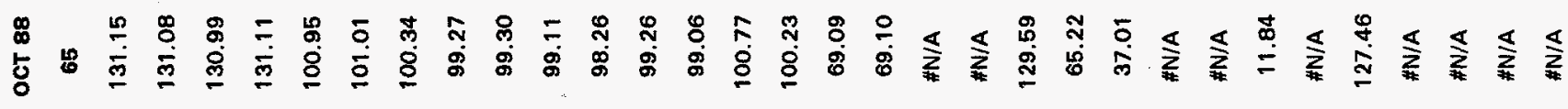
ํํํำ

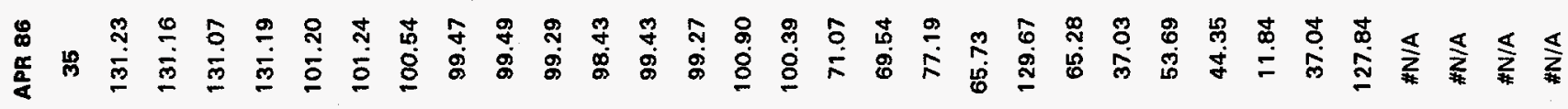

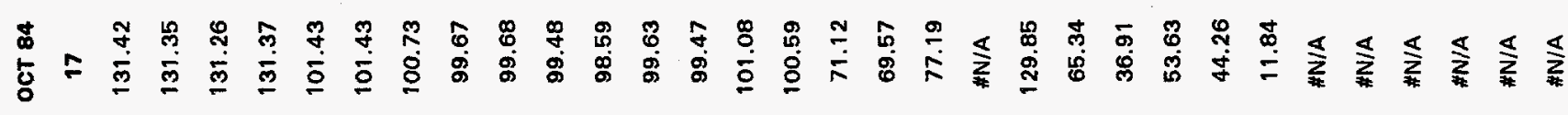

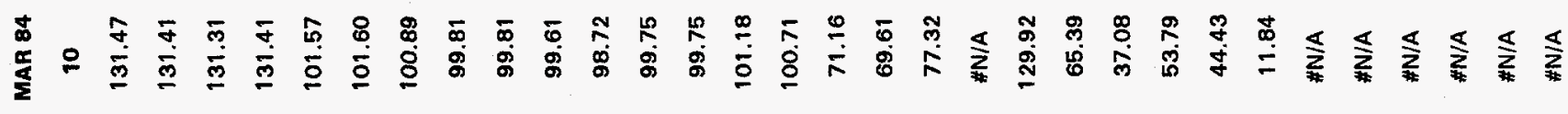

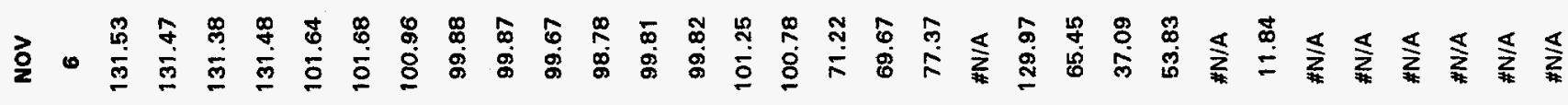

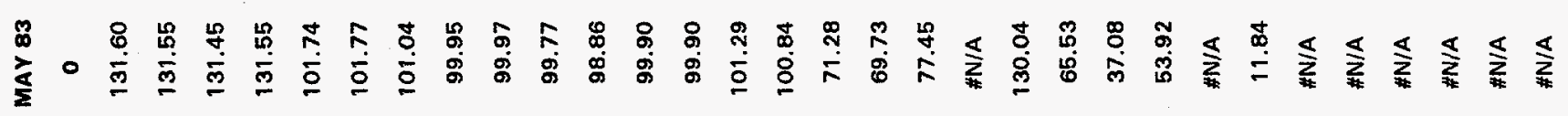

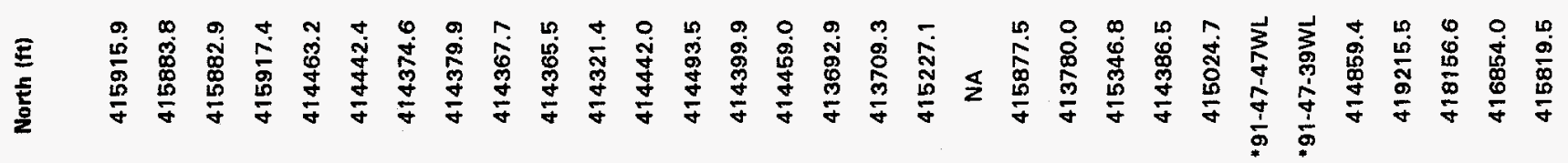

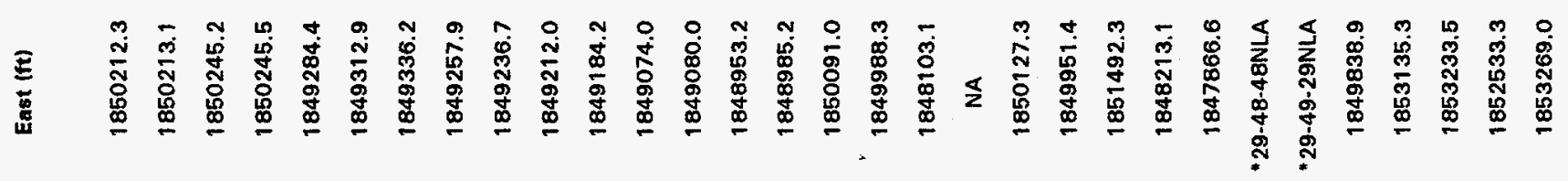

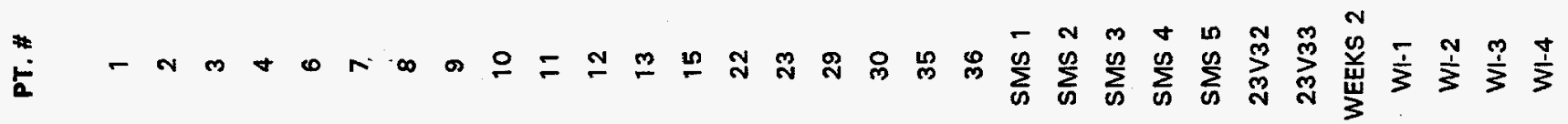




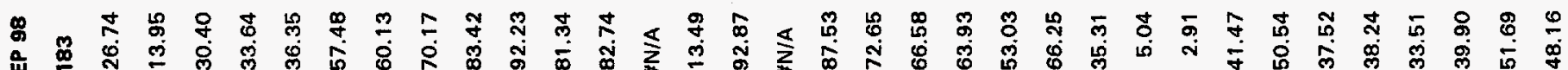

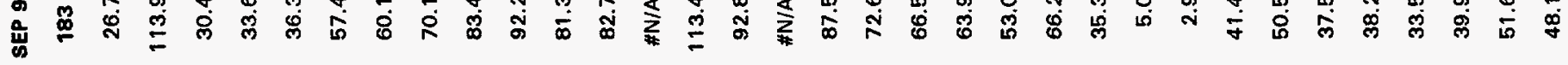

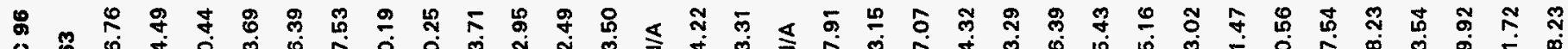

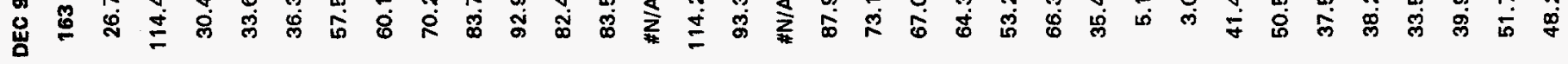

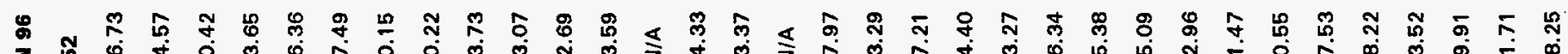

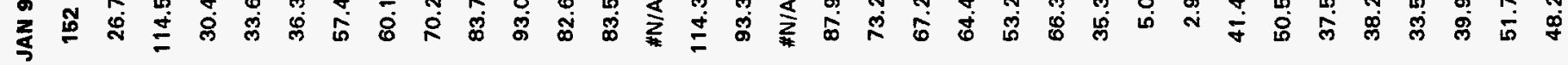
\& 芭

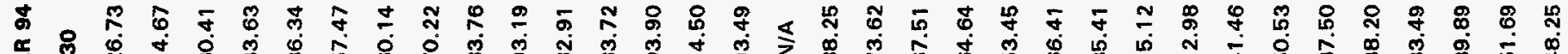

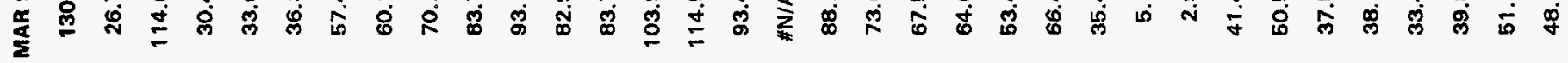
న

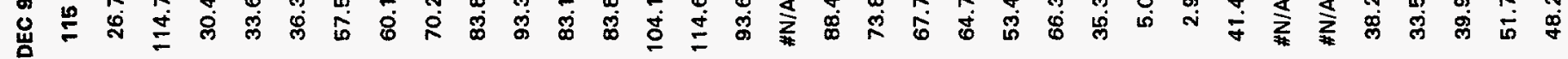

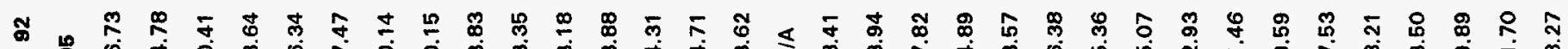

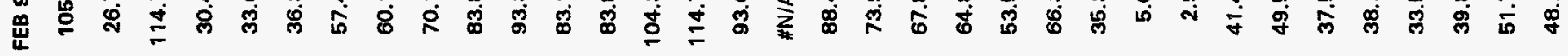
- 5 范 苑

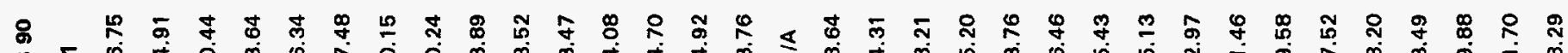

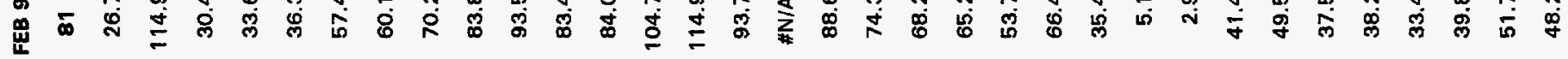

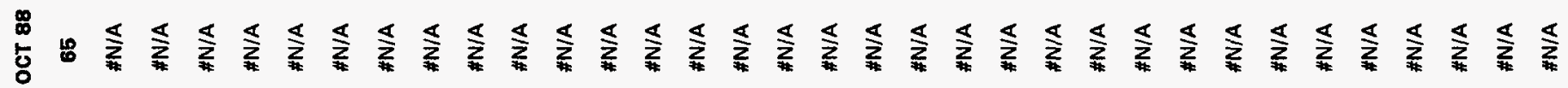
全 邑竞

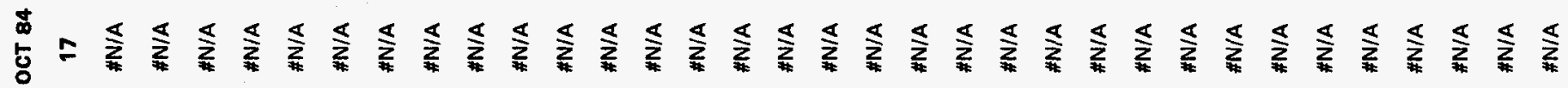

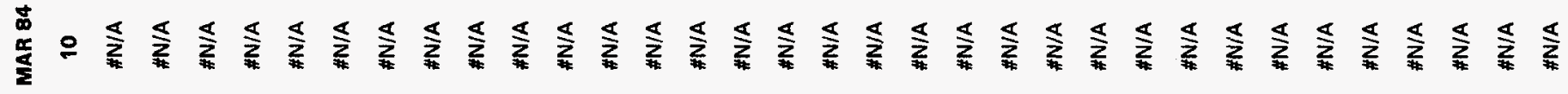
$\partial^{0}$ 总

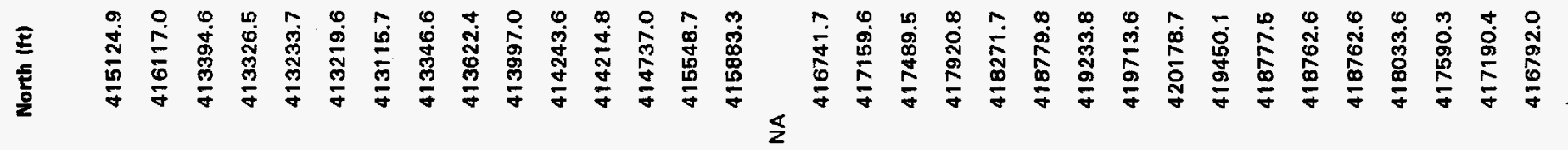

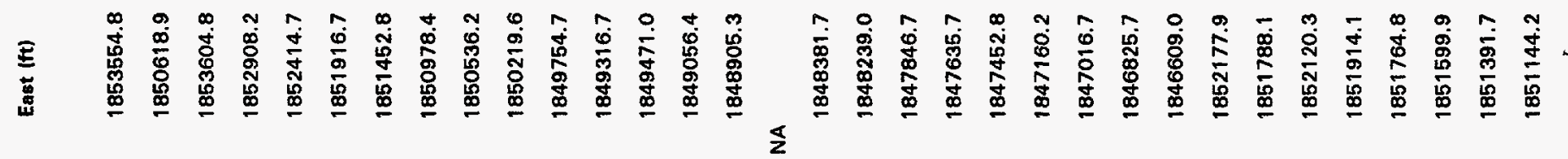

* L $\quad$ L 


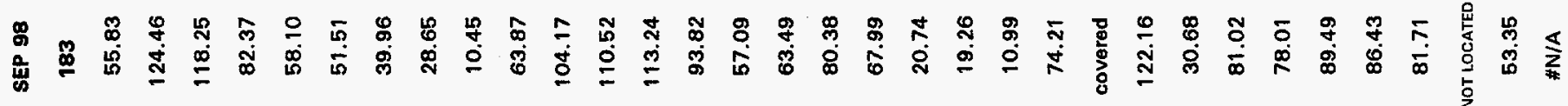

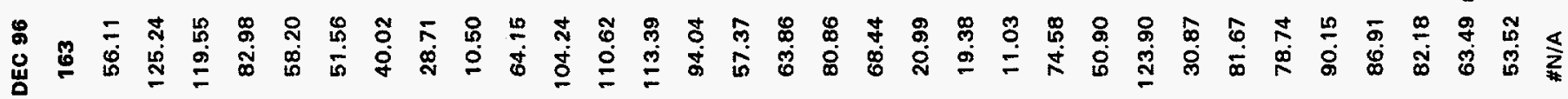
\&

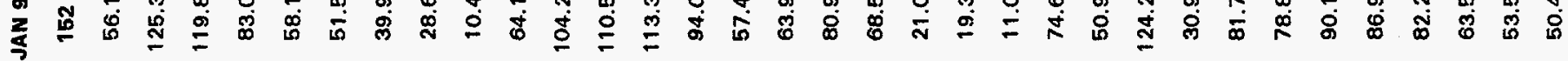

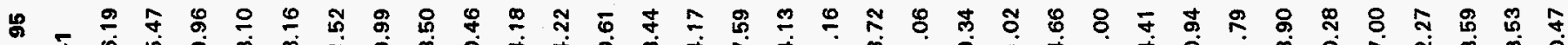

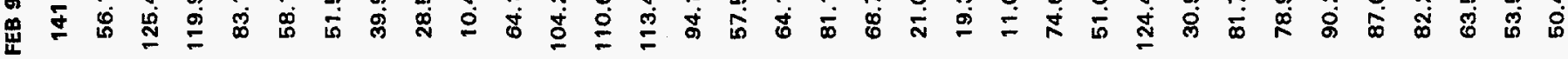

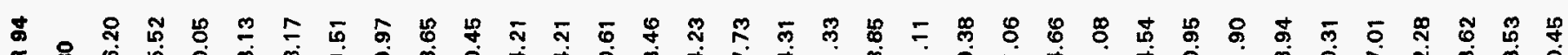

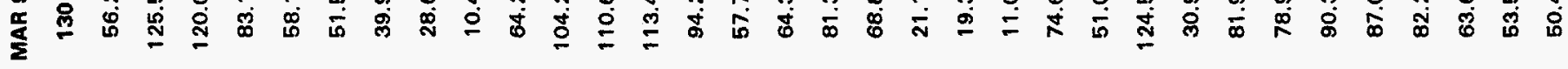
응 눙 苅 并 ร

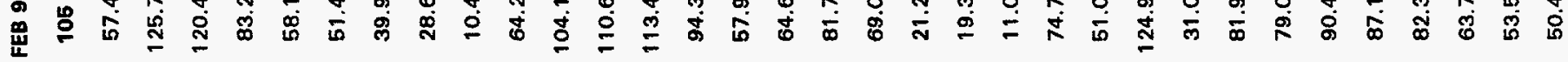

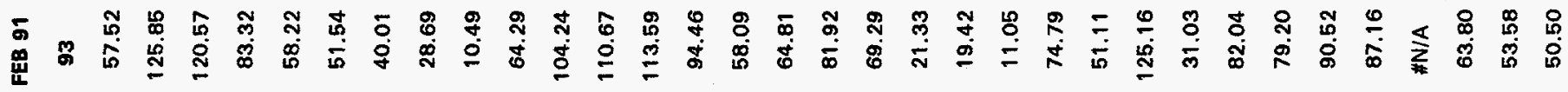

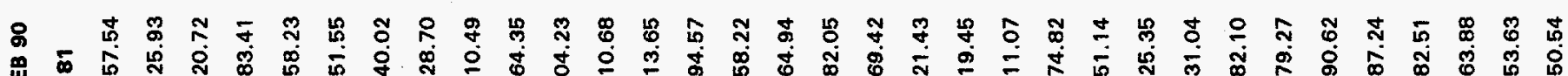

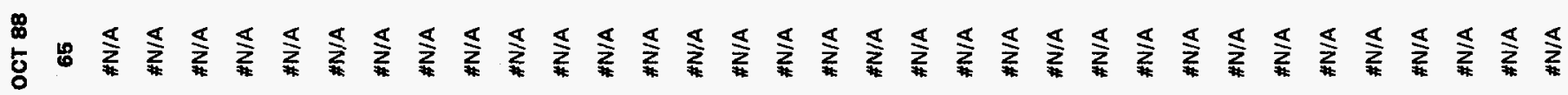

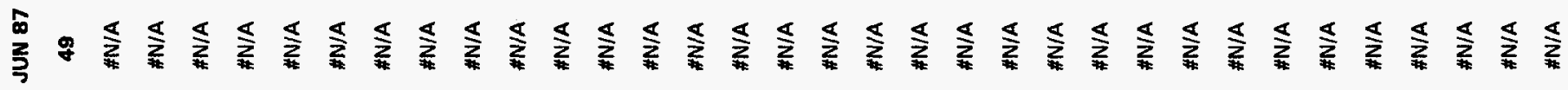

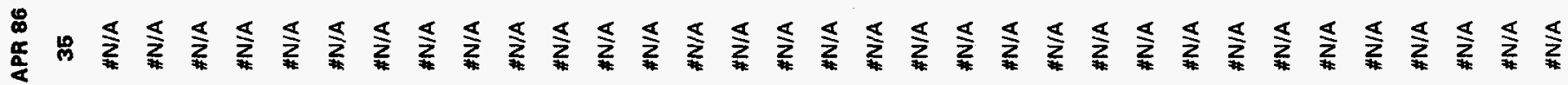

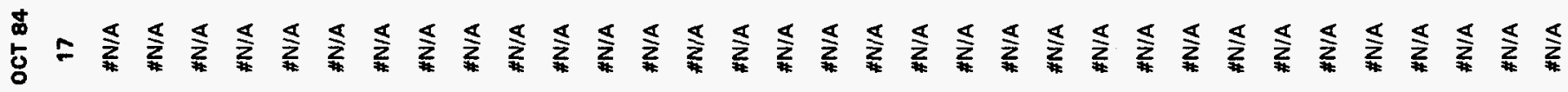
戛

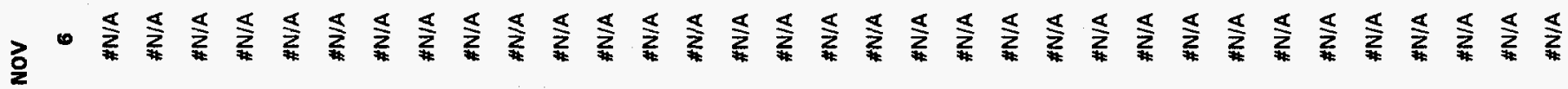

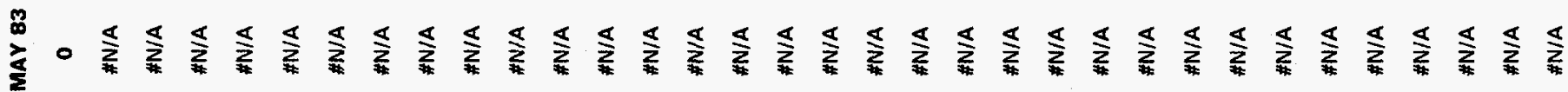

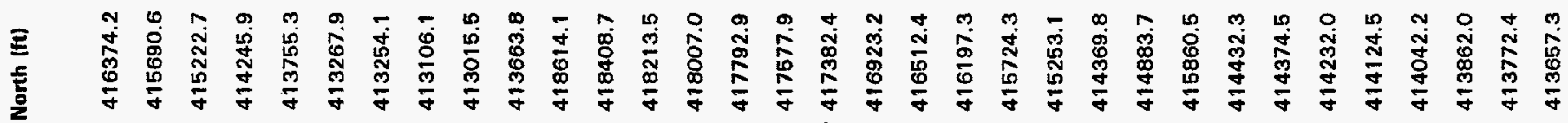

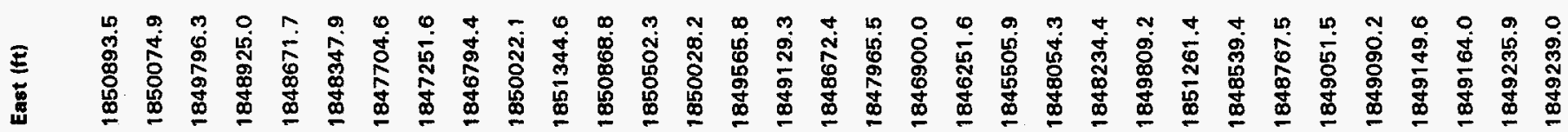

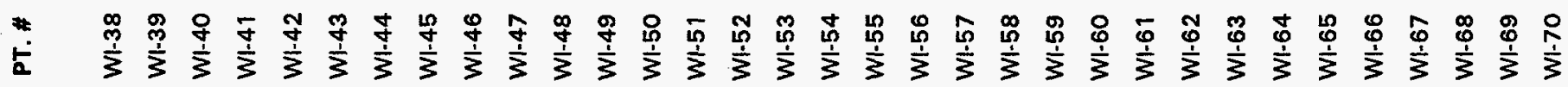




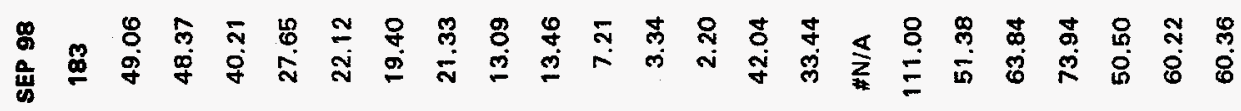

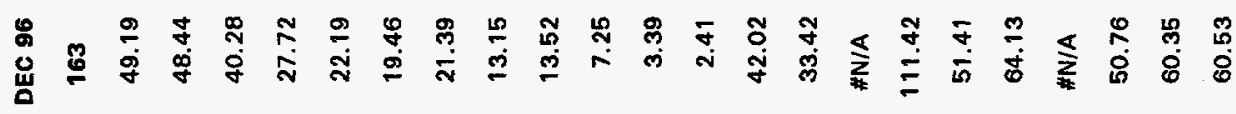

造

兽

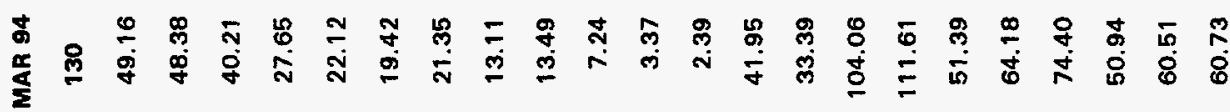

న

范

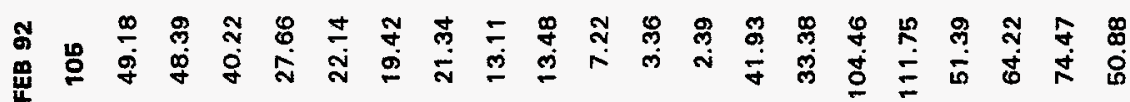

可

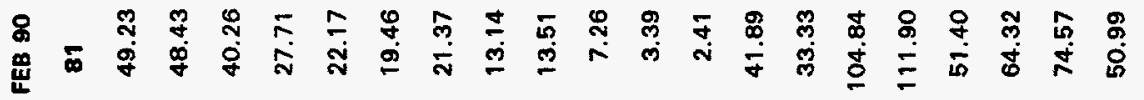

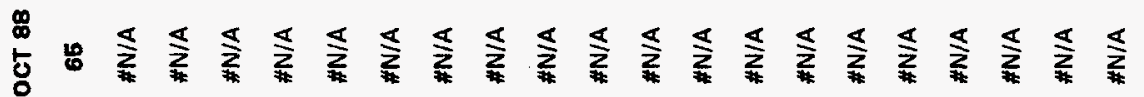

怘

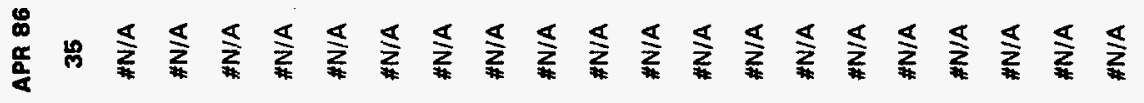

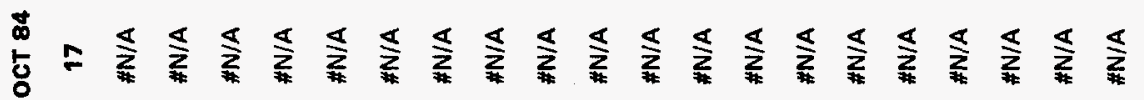

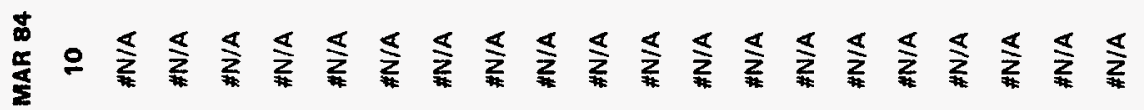

主

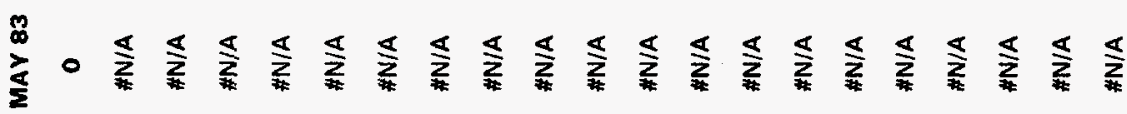

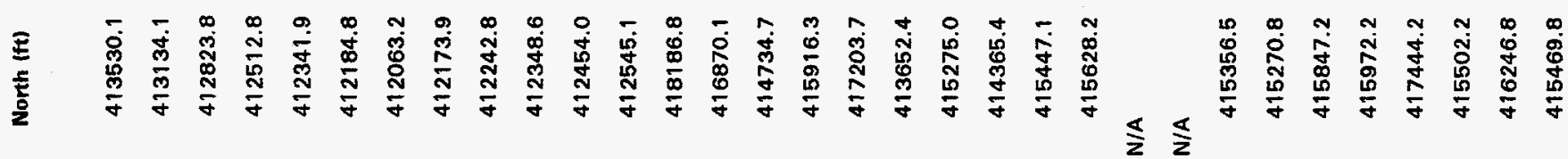

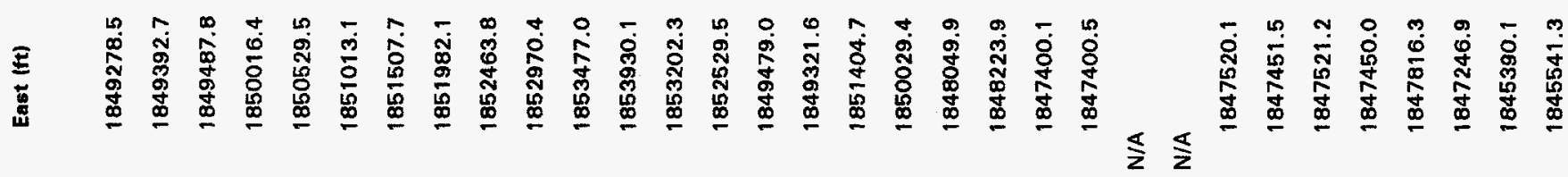

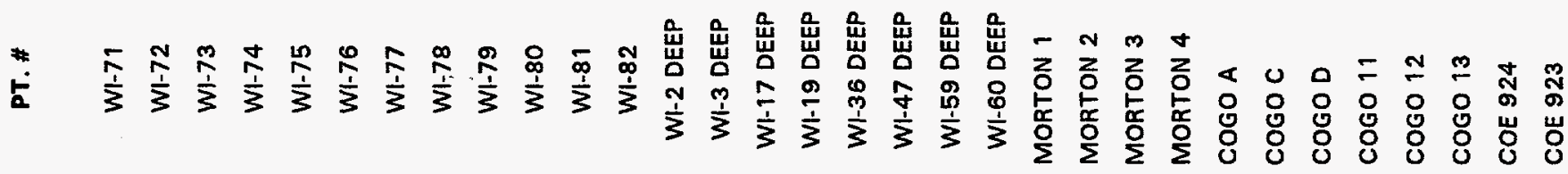

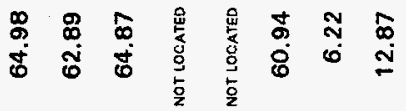

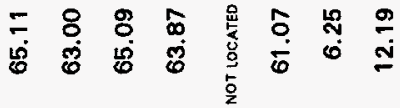

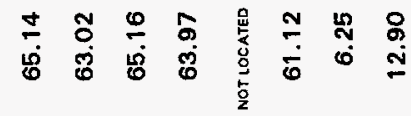

然

番 
Appendix 2

Historic Subsidence Rates at Weeks Island 


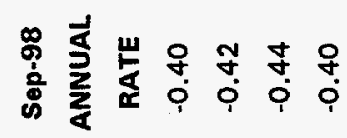

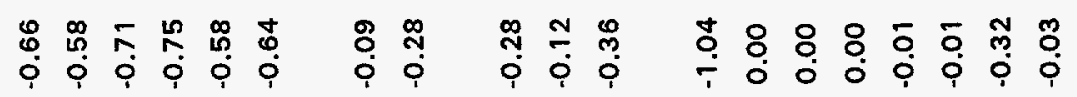

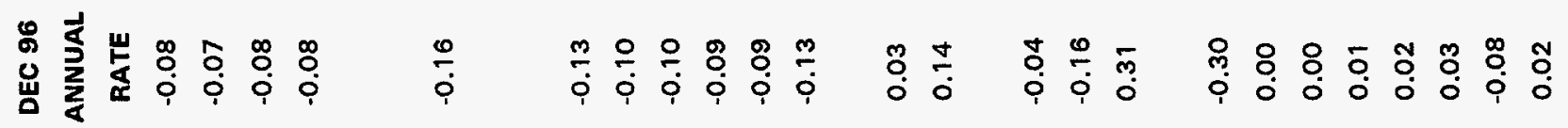

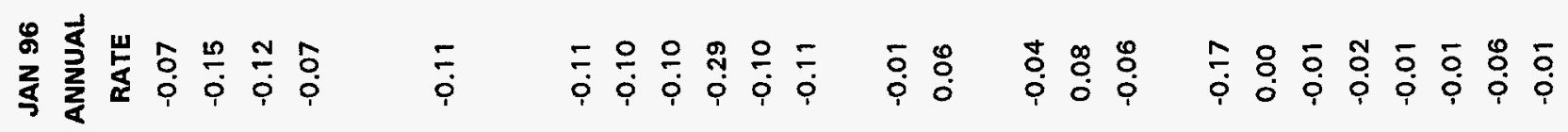

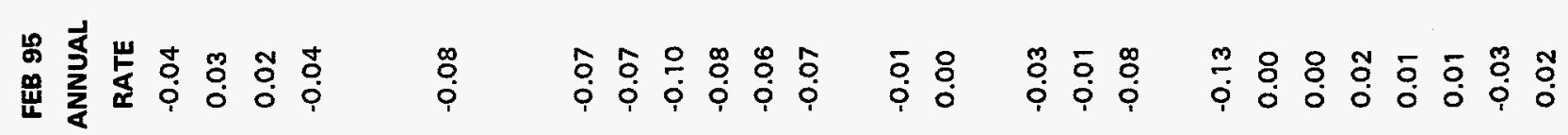

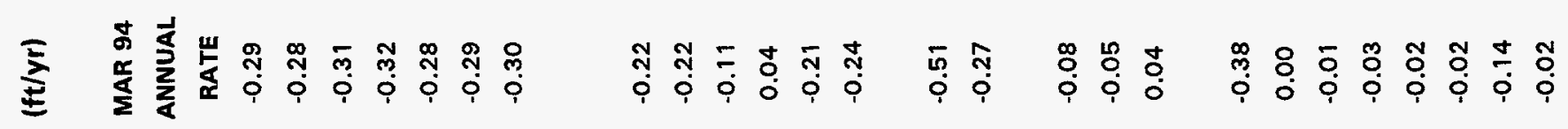
离

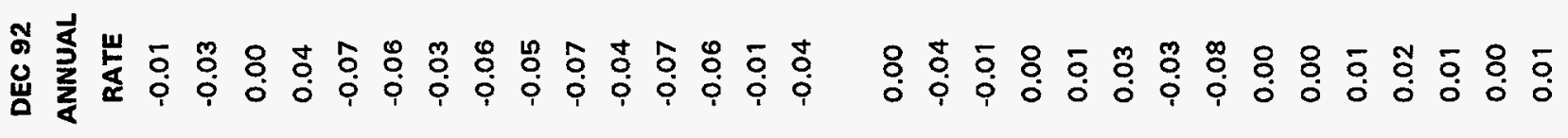

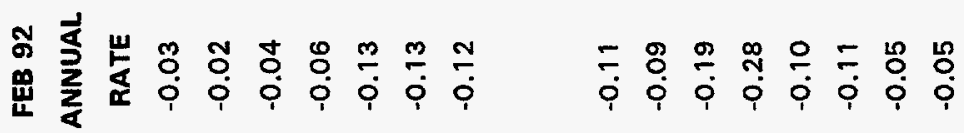

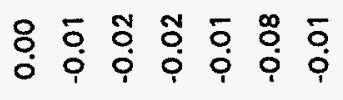

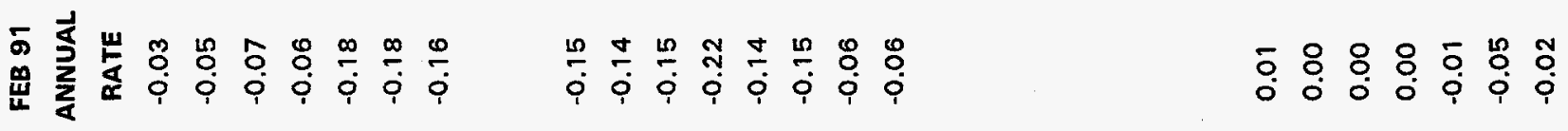

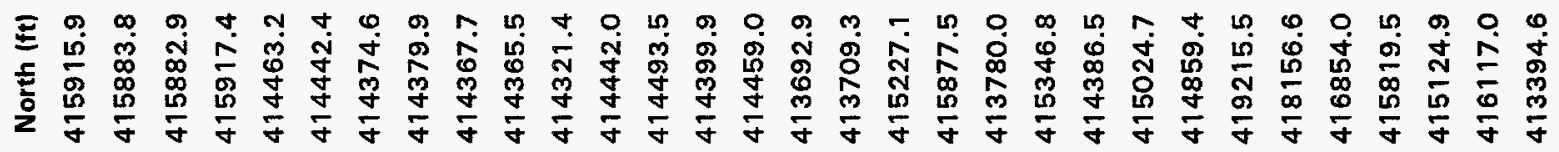

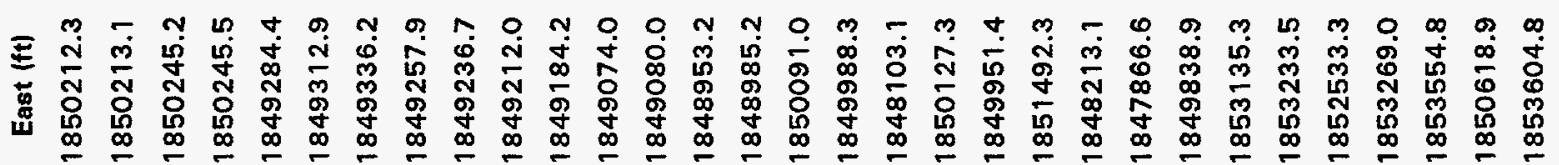

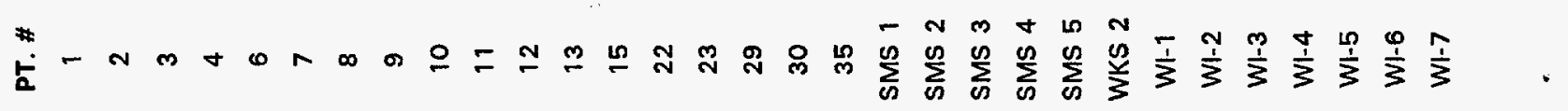




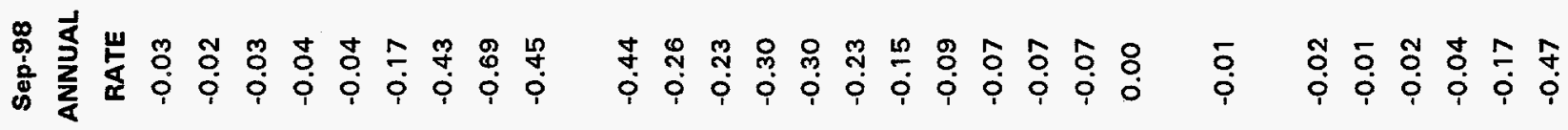

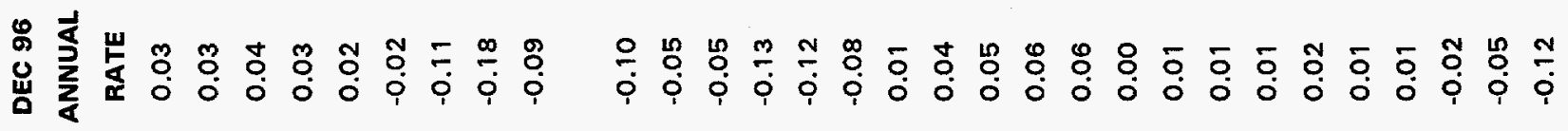

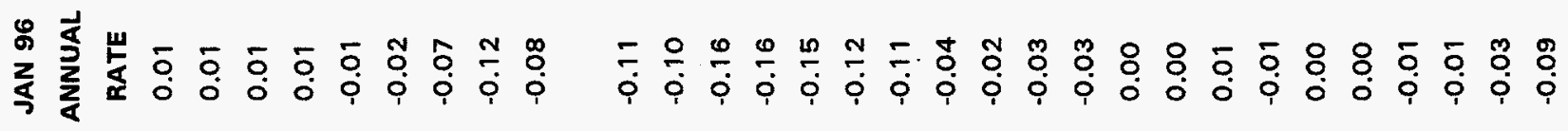

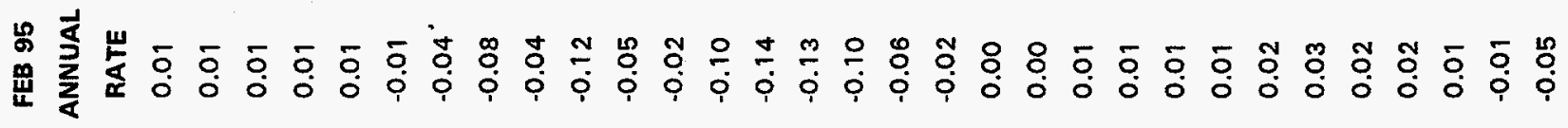

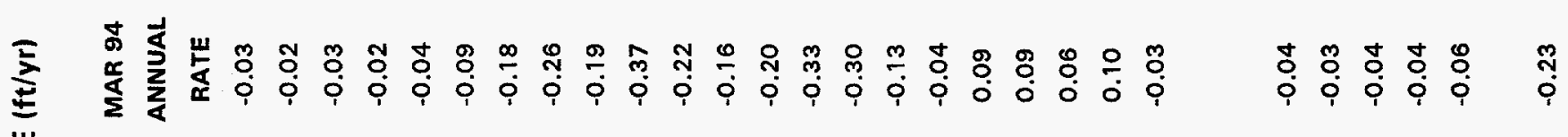
峞

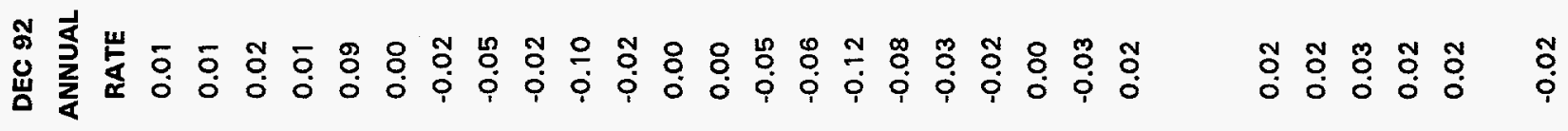
峞

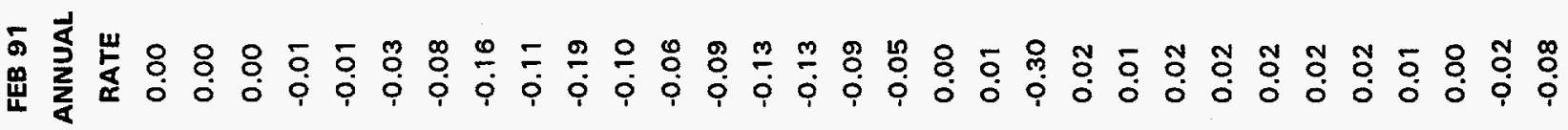

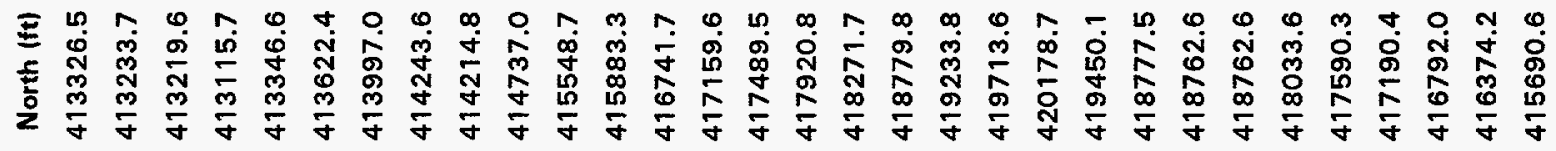

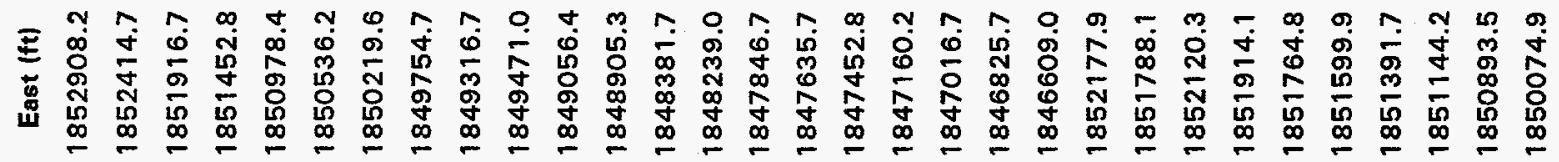
\# 


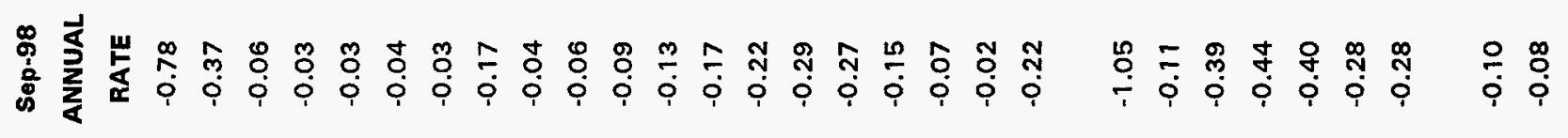

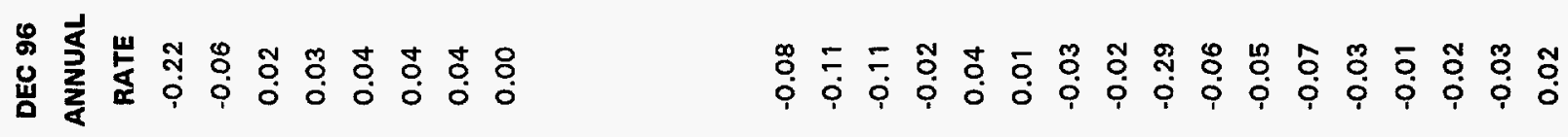

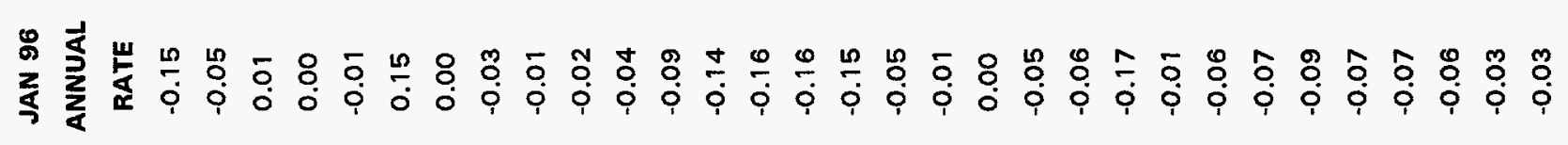

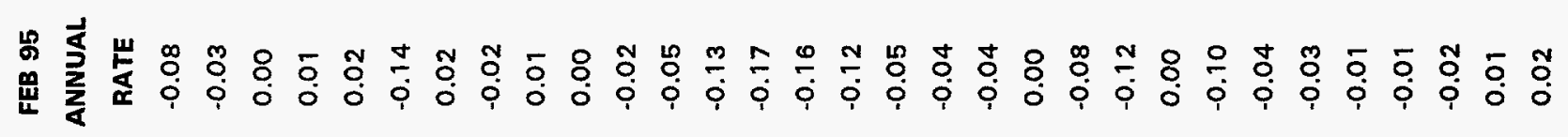

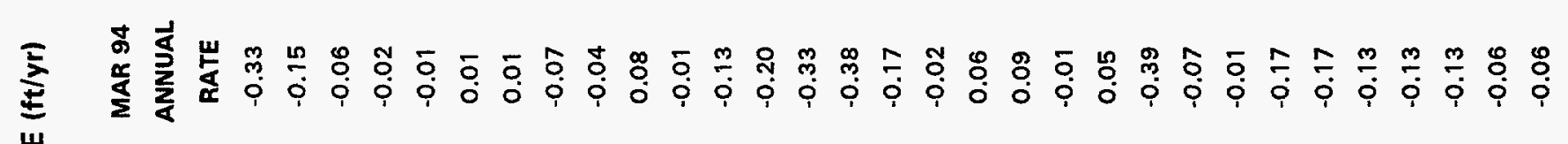

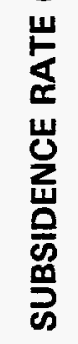

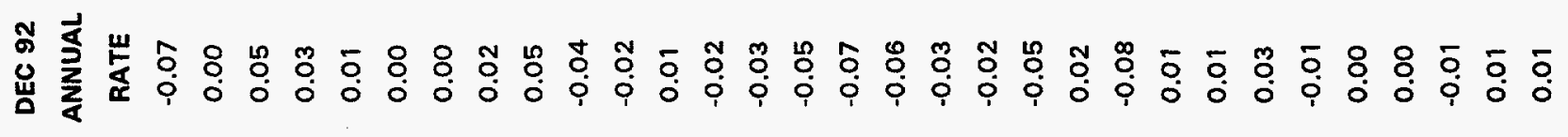

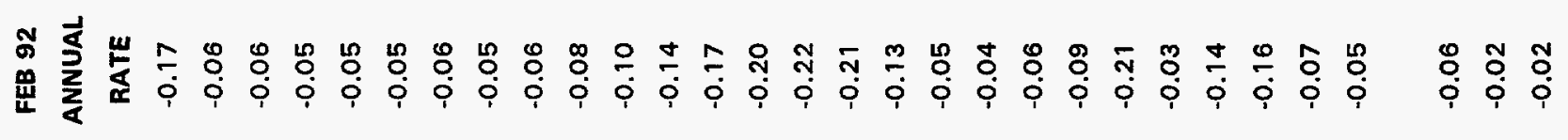

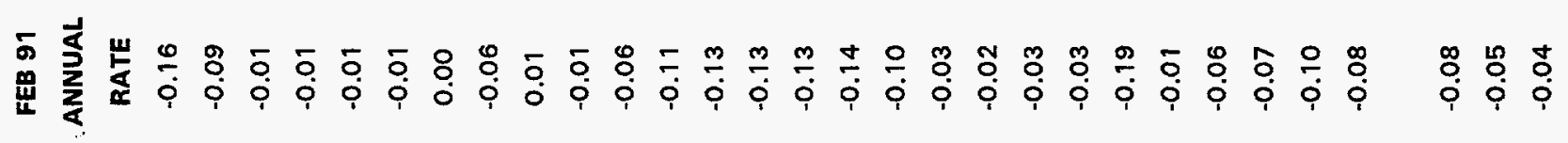

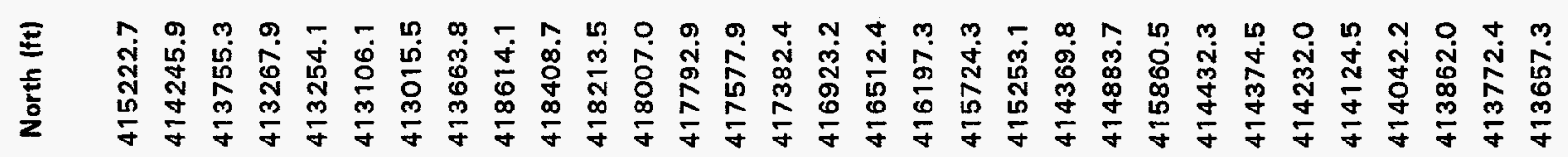

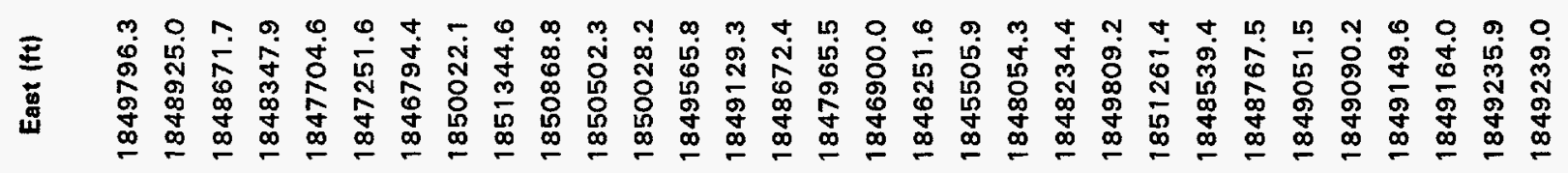

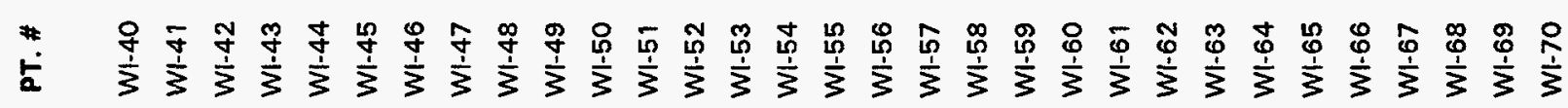




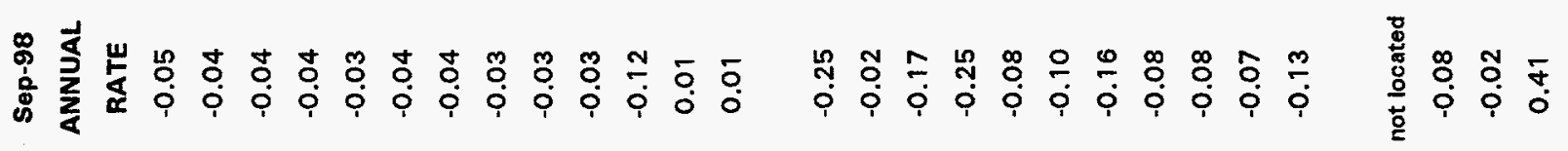

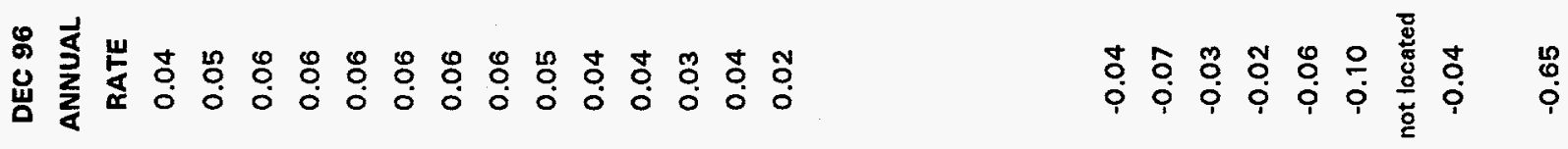

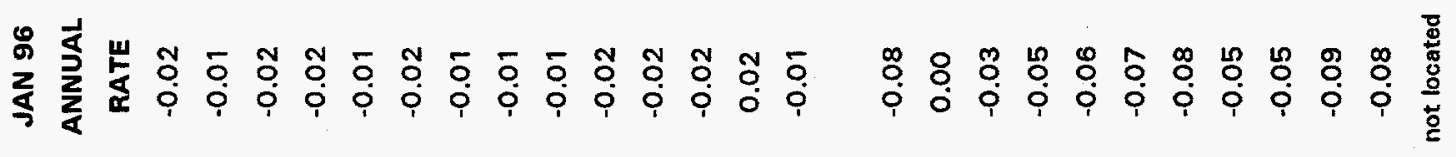

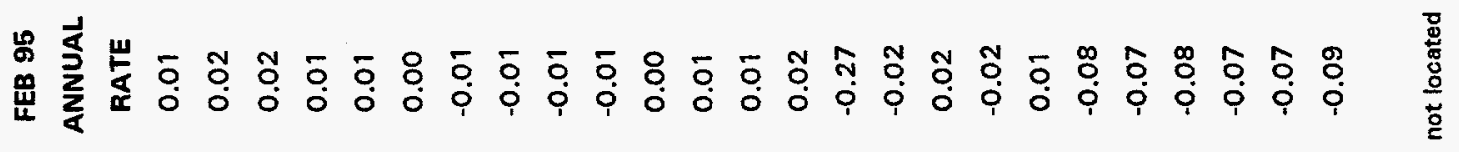

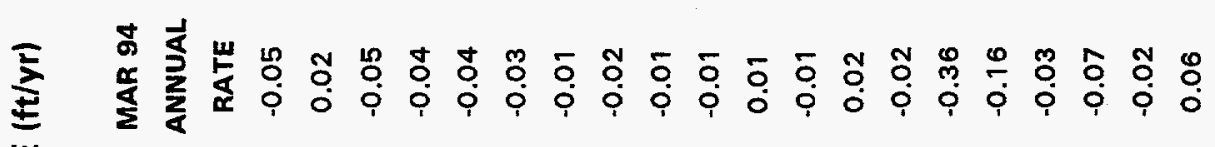

晨

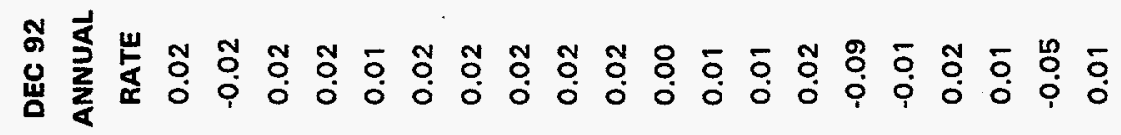

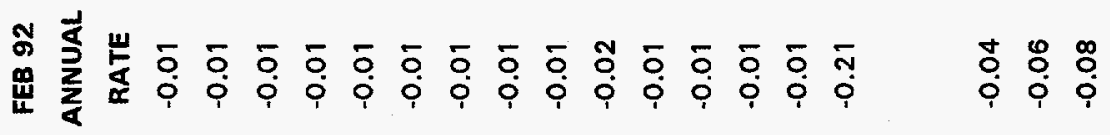

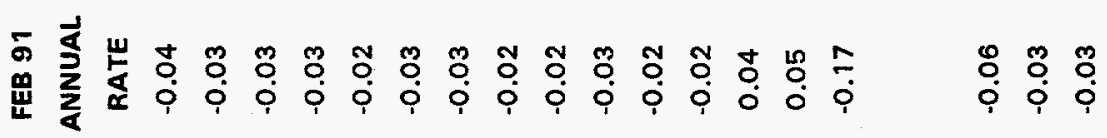

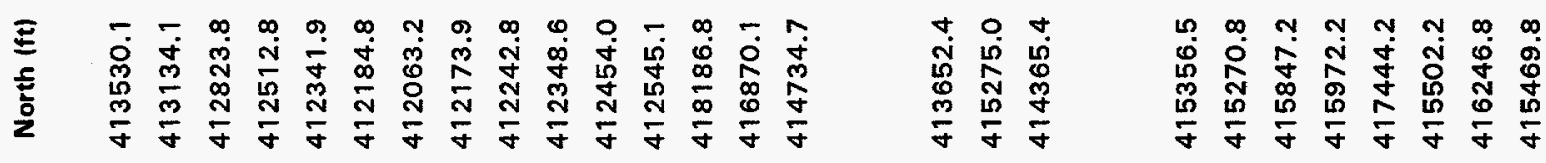

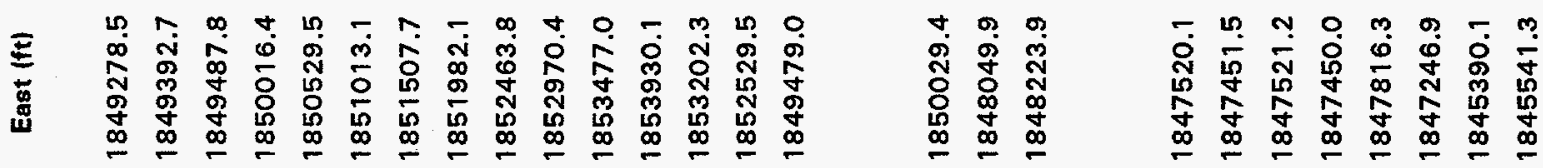

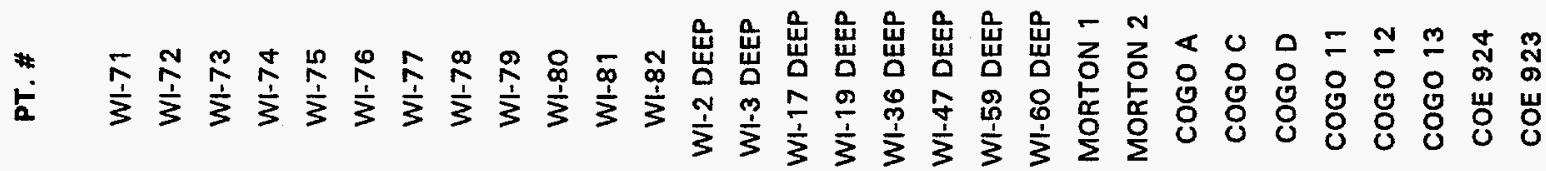




\section{Appendix 3}

memo: S. J. Bauer to R. Myers dated 2/24/98

"Implications of Recent Subsidence Measurements at Weeks Island - CORRECTED" 


\title{
Sandia National Laboratories
}

\author{
date: $\quad$ February 24,1998 \\ Albuquerque, New Mexico 87185-0706 \\ to: $\quad$ R. Myers DOE SPR PMO FE 4422
}

from: $\quad$ S. J. Bauer 6113, MS0706

subject: Implications of Recent Subsidence Measurements at Weeks Island - CORRECTED

Elevation measurements have been taken at Weeks Island since May of 1983 to facilitate our understanding of subsidence around the SPR site. These measurements have been made annually and have been tied to a benchmark off the island. It was decided to supplement this annual data with quarterly elevation measurements during the year that included the oil withdrawal and subsequent brine refill. These quarterly measurements (conducted 3/97,7/97 and 9/97) are in the immediate vicinity of Sinkhole \#1, a site of historic localized subsidence. It was thought that these measurements would help identify potential localized effects in this vicinity.

The monuments (Figure 1) surveyed in the quarterly measurements include WI-68 through WI-73 which trend north northwest from the railroad track and are located west and south of Sinkhole \#1, WI-47 deep southwest of Sinkhole \#1, and WI-12 through 16 which follow the road from east to west, passing Sinkhole \#1. Monument WI-15 is physically closest to Sinkhole \#1.

The quarterly measurements are not tied to the benchmark off the island. These measurements have been analyzed by comparing them to monument WI-73. Monument WI-73 is about 1300 feet from and south-southwest of the sinkhole; it is also about the same distance from the mine boundary. Therefore WI-73 should not be effected dramatically by mine related subsidence.

The vertical displacement for each station relative to WI-73 versus time is plotted in Figure 2 beginning in 2/90. All data presented in Figure 2 are derived by subtracting the elevation change for Monument WI-73 from that observed at a given station. The last 3 measurements plotted constitute the recent data collected for this report (3/97, 7/97, and 9/97). Data plotted begins in 2/91 and runs until $9 / 97$. The data trend indicates a slight increase in the downward displacement rate since 1/96. While it appears that the subsidence rates have 
been greatest for monuments in the immediate vicinity of the sinkhole, the rates appear to be historically uniform.
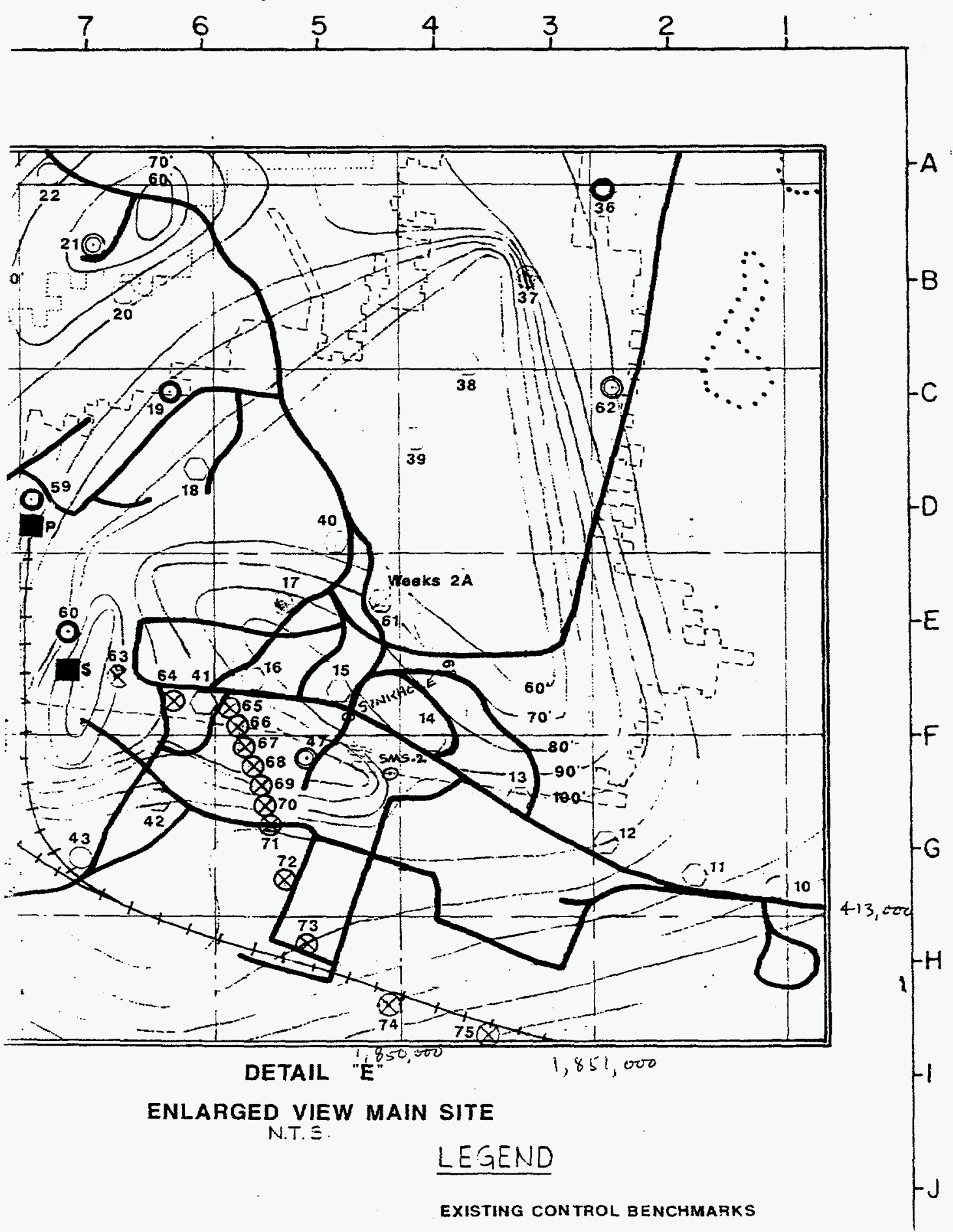

Figure 1. Location map for monuments. 


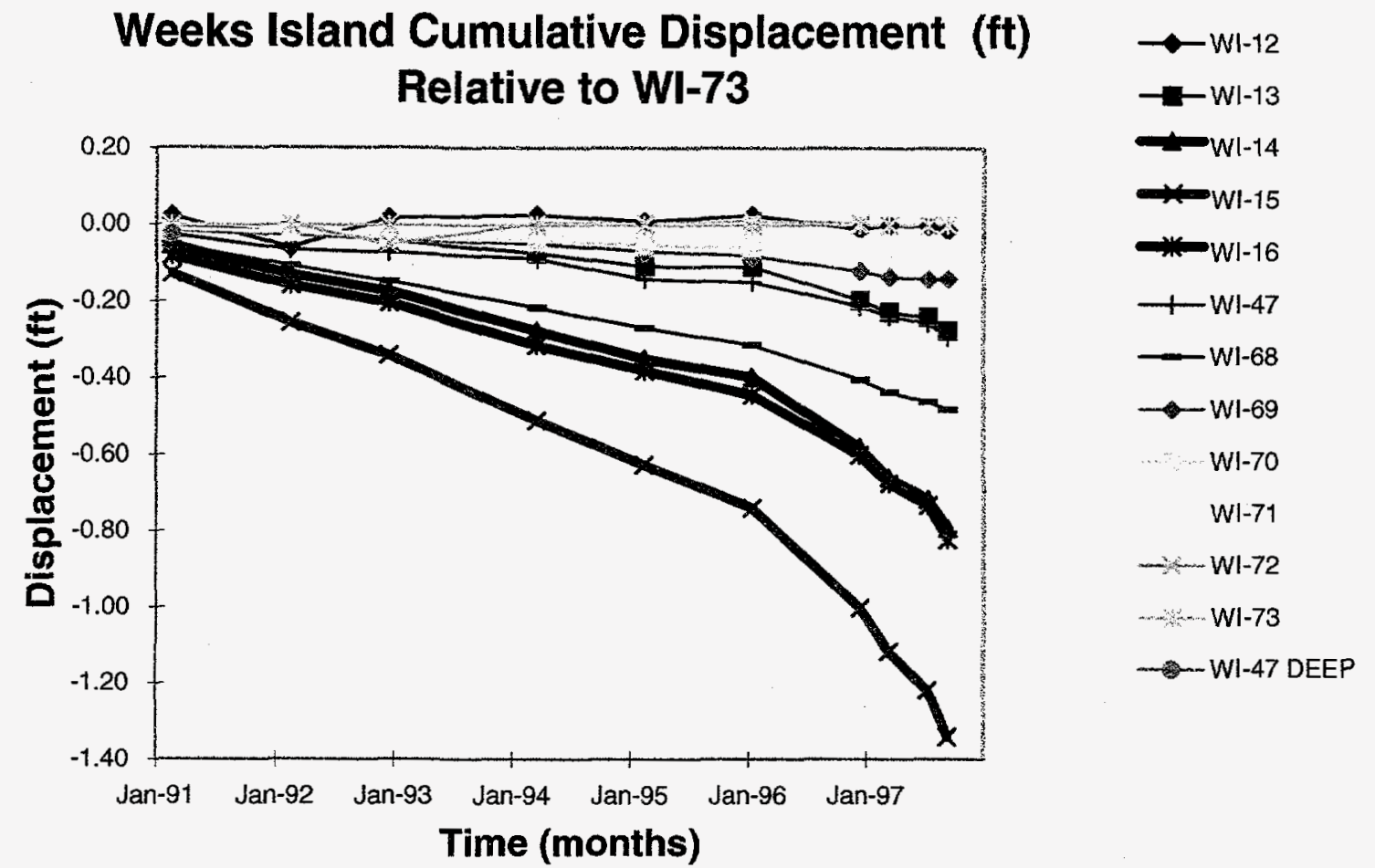

Figure 2. Weeks Island cumulative displacement (ft) relative to monument WI73.

Figure 3 presents subsidence displacements considered relative to the benchmark off the site through $12 / 96$. This presentation is made to provide a comparison with the WI-73 method. The differences observed are small, except that the downward trend in the data after $1 / 96$ is less for the "fixed" benchmark data set. This implies that using the WI-73 method has some validity, however it is unclear if the magnitudes in downward displacement are really as great as indicated in Figure 2; this could be an artifact of the analysis method. The recent measurements will be reassessed with the next fixed benchmark study scheduled for this spring.

In Figure 2 the subsidence rate for WI- 15 is consistently greater than the others measured beginning in 2/91. Although WI-15 is closest to the sinkhole, its movement may be due primarily to its position relative to the mine center.

There is a slight increase in subsidence rate after the 1/96 measurement. This is consistent with the timing for oil withdrawal. 


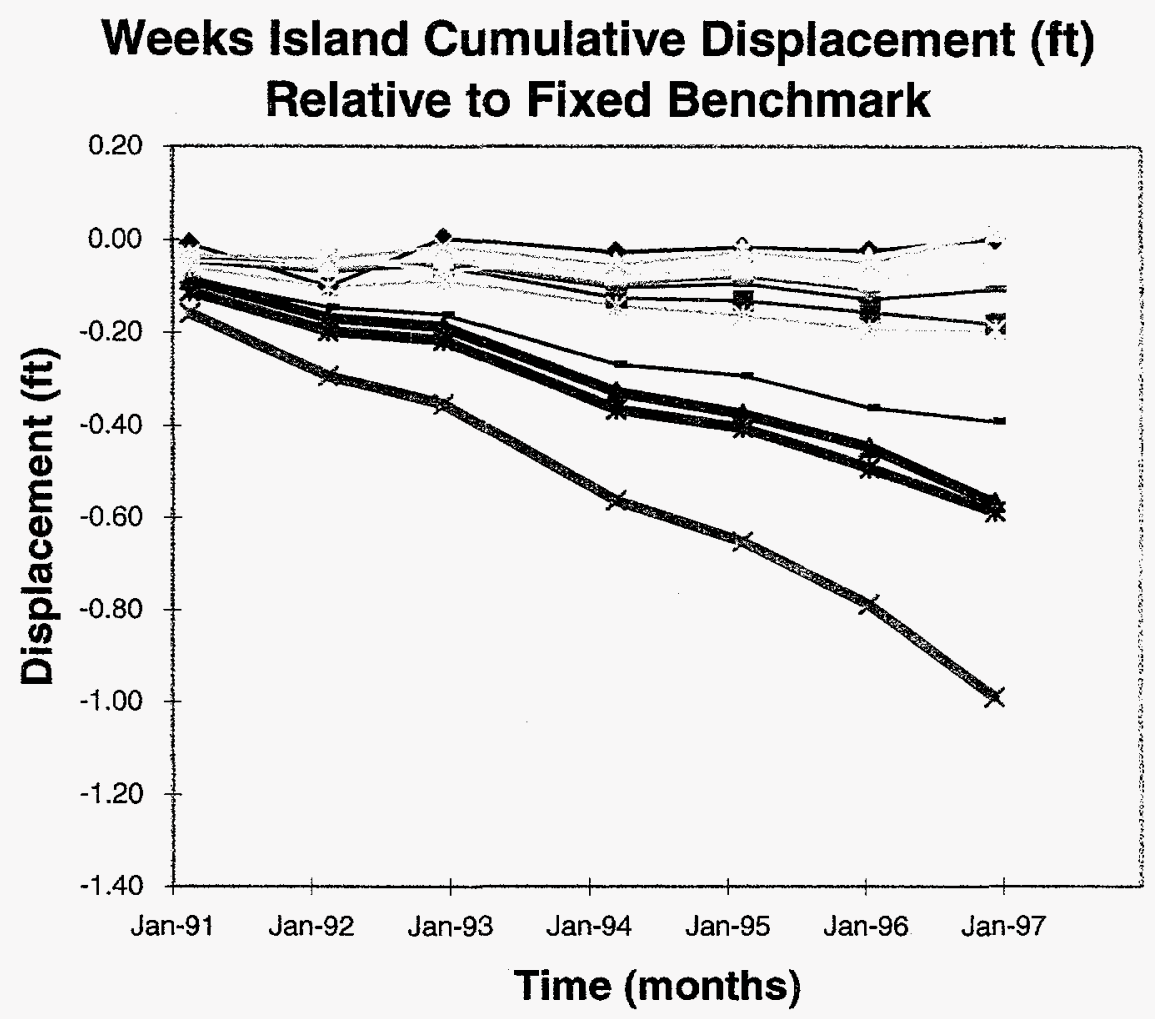

- WI-12

$-m-W \mid-13$

$\therefore$ WI-14

$W \mid-15$

$-W=W \mid-16$

$\longrightarrow W 1-68$

$-W 1-69$

$-W 1-70$

W1-71

W1-72

WI-73

WI-47

DEEP

Figure 3. Weeks Island cumulative displacement ( $\mathrm{ft}$ ) relative to fixed benchmark for all monuments included in this study. 
In Figure 4, WI-14, 15, 16 (already discussed) are presented as well as WI- 39 and WI-40. The comparison is made to demonstrate that WI14,15 , and 16 data are consistent in magnitude with historical data elsewhere over the mine.

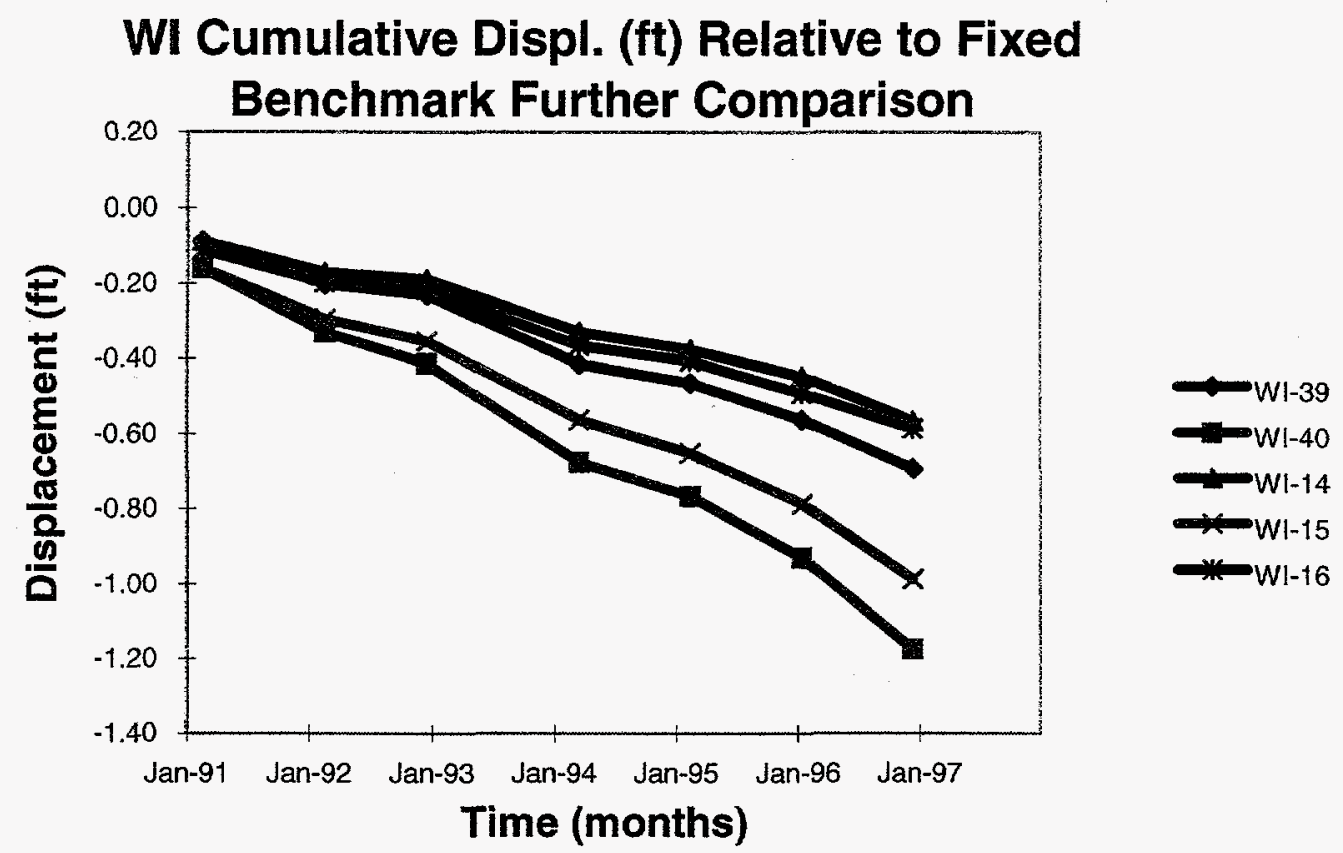

Figure 4. Weeks Island cumulative displacement (ft) relative to fixed benchmark for selected monuments included in this study as well as other monuments for comparison.

We conclude that subsidence near the sinkhole is consistent with observed subsidence over other areas of the mine.

Copy to:

N. Shourbagi DOE SPR PMO FE 4421

J. Barrington DM EF 21

J. McGough DM EF 31

J. McHenry DM EF 25

R. Lynch 6100 MS 0701

J. Linn 6113 MS 0706

Staff $\quad 6113$ MS 0706 


\section{Distribution}

U.S. Department of Energy (2) Strategic Petroleum Reserve 1000 Independence Avenue SW Washington, D.C. 20585

Attn: D. Johnson, FE 421

D. Buck, FE 421

U.S. Department of Energy (13) Strategic Petroleum Reserve 900 Commerce Road East

New Orleans, LA 70123

Attn: W. C. Gibson, FE 44

J. C. Kilroy, FE 443

W. Poarch, FE 4432

G.B. Berndsen, FE 443.1 (5)

N. Shourbaji, FE 4421

J. Culbert, FE 443

R. Myers, FE 4421

$\operatorname{TDCS}(2)$

U.S. Department of Energy (3)

Strategic Petroleum Reserve

Attn: M.B. Jackson, FE 4421.6, DOE SPR WI (3)
Sandia Internal: (25)

MS 0701 L. Shephard, 6100

MS 0706 J. Linn, 6113

MS 0706 B. Ehgartner, 6113

MS 0706 T. Hinkebein, 6113

MS 0706 D. Munson, 6113

MS 0706 C. Williams, 6113

MS 0706 S. Bauer, 6113 (15)

MS 9018 Cen. Tech. Files, 8940-2

MS 0899 Tech. Library, 4916 (2)

MS 0619 Review and Approval Desk for DOE/OSTI, 15102

DynMcDermott (4)

850 South Clearview Parkway

New Orleans, LA 70123

Attn: L. Eldredge, EF 20

K. Mills, EF 20

J. McHenry, EF 25

J. Barrington, EF 31

PB-KBB Inc.

11767 Katy Freeway

P O Box 19672

Houston, TX 77224

Attn: S. Raghuraman 